Document downloaded from:

http://hdl.handle.net/10251/165482

This paper must be cited as:

Rojas-Buzo, S.; Corma Canós, A.; Boronat Zaragoza, M.; Moliner Marin, M. (2020). Unraveling the Reaction Mechanism and Active Sites of Metal-Organic Frameworks for Glucose Transformations in Water: Experimental and Theoretical Studies. ACS Sustainable Chemistry \& Engineering. 8(43):16143-16155. https://doi.org/10.1021/acssuschemeng.0c04398

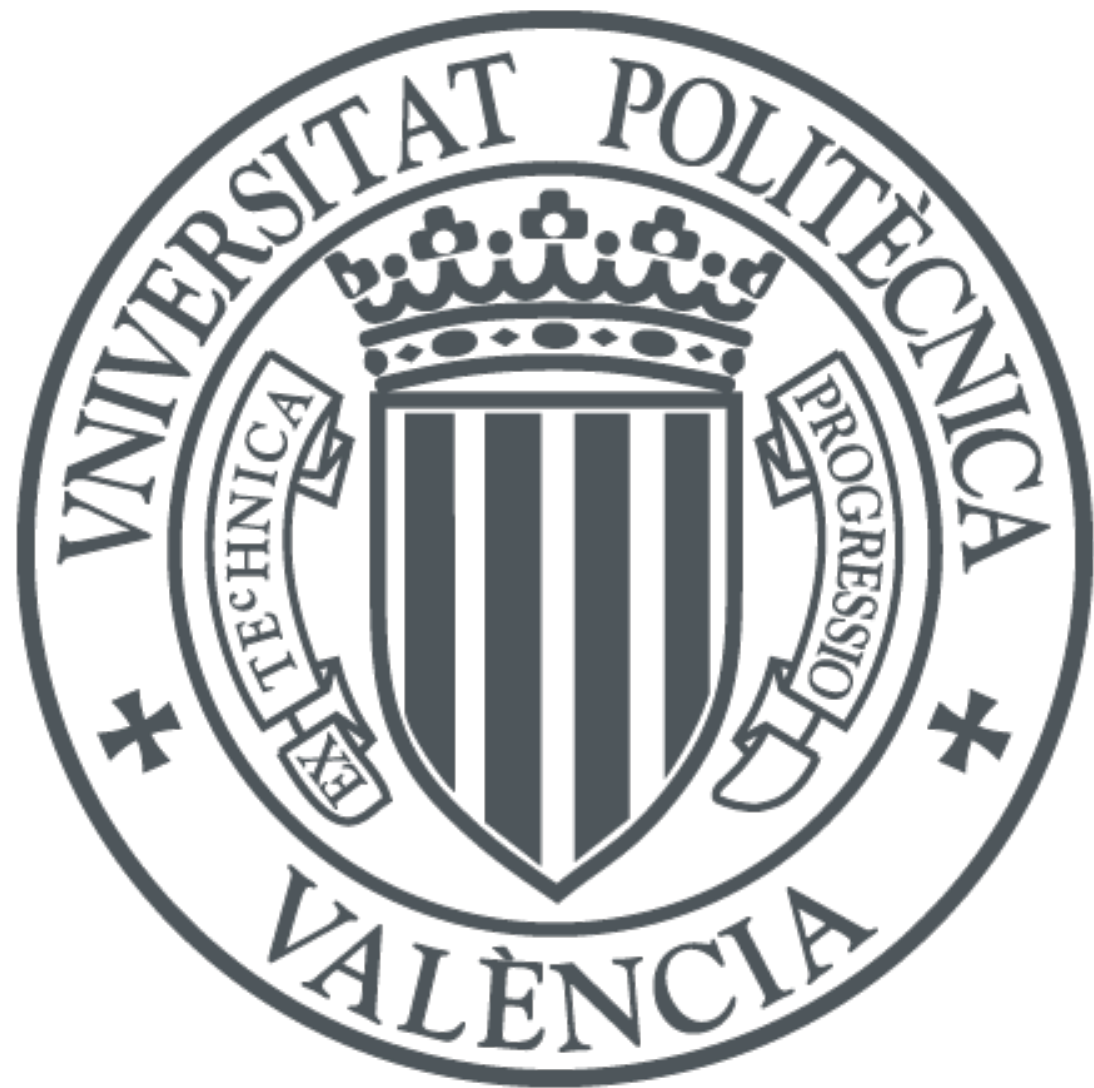

The final publication is available at

https://doi.org/10.1021/acssuschemeng.0c04398

Copyright American Chemical Society

Additional Information

This document is the Accepted Manuscript version of a Published Work that appeared in final form in ACS Sustainable Chemistry \& Engineering, copyright (C American Chemical Society after peer review and technical editing by the publisher. To access the final edited and published work see https://doi.org/10.1021/acssuschemeng.0c04398 


\title{
Unraveling reaction mechanism and active sites of metal-organic frameworks for glucose transformations in water: experimental and theoretical studies
}

\author{
Sergio Rojas-Buzo, ${ }^{1}$ Avelino Corma, ${ }^{1}$ Mercedes Boronat ${ }^{* 1}$ and Manuel Moliner ${ }^{* 1}$ \\ ${ }^{1}$ Instituto de Tecnología Química, Universitat Politècnica de València - Consejo Superior de Investigaciones \\ Cientificas, Av. de los Naranjos, s/n, 46022 Valencia, Spain \\ * Corresponding author: e-mail address: mmoliner@itq.upv.es
}

e-mail address: boronat@itq.upv.es

\begin{abstract}
The catalytic performance of two different metalorganic frameworks, UiO-66 and MOF-808, containing Lewis acid active sites has been evaluated for the transformation of glucose in water, and compared with that of analogous Lewis acid Zr-Beta zeolite. While fructose is the main product obtained on Zr-Beta, the mannose production increases when using $\mathrm{Zr}-\mathrm{MOF}$ as catalysts. Kinetic studies reveal a lower activation energy barrier for glucose epimerization to mannose when using Zr-MOF catalysts ( 83-88 and $\sim 100 \mathrm{~kJ} / \mathrm{mol}$ for glucose epimerization and isomerization, respectively). ${ }^{13} \mathrm{C}$ NMR study using ${ }^{13} \mathrm{C} 1$-labelled glucose allows confirming that on $\mathrm{Zr}-\mathrm{MOF}$ catalysts mannose is exclusively formed following the glucose epimerization route through 1,2intramolecular carbon shift, whereas the two step glucose $\rightarrow$ fructose $\rightarrow$ mannose isomerization via 1,2-intramolecular proton shifts is the preferred pathway on Zr-Beta. A computational study reveals a different mode of adsorption of deprotonated glucose on Zr-MOFs that allows decreasing the activation barrier for the 1,2intramolecular carbon shift. The combination of spectroscopic, kinetic and theoretical studies allows unraveling the nature of the metal sites in $\mathrm{Zr}$-MOFs and $\mathrm{Zr}$-Beta catalysts and to propose a structure-activity relationship between the different Lewis acid sites and the glucose transformation reactions. The results presented here could permit new rationalized MOF catalyst designs with the specific active sites to facilitate particular reaction mechanisms.
\end{abstract}

KEYWORDS: MOFs, Lewis acids, glucose, mannose, epimerization, structure-activity

\section{INTRODUCTION}

In the last two decades, many efforts have focused on attempting the efficient transformation of biomass to high value products. ${ }^{1,2}$ If one considers the possible biomass-derived platform molecules, hexoses are the most abundant monosaccharides present in nature, and, consequently, there is a growing interest on their transformation into industrially-relevant chemicals. ${ }^{3}$ Glucose isomerization reaction has been extensively applied to produce fructose, ${ }^{4,5}$ which not only is a well-known sweetener used as an alternative to conventional table sugar (sucrose) ${ }^{6}$ but also has emerged as a key intermediate in the synthesis of biofuel precursor 5-hydroxymethylfurfural $\quad(\mathrm{HMF}){ }^{7} \quad$ Traditionally, glucose isomerization to fructose has employed bio-enzymatic catalytic systems, such as D-Xylose Isomerase XI, containing $\mathrm{Mg}^{2+}$ or $\mathrm{Mn}^{2+}$ inside hydrophobic pockets. ${ }^{8}$ However, these bio-catalysts are extremely sensitive to temperature and $\mathrm{pH}$ modifications that can irreversibly denaturalize the enzyme structure and, in addition, they are barely separated from the reaction medium. These limitations were overwhelmed by introducing isolated Lewis acidic metal sites within hydrophobic pure-silica molecular sieves, i.e. Sn-Beta,,${ }^{9,10}$ acting as very active and stable heterogeneous catalysts for the glucose isomerization to fructose in water. ${ }^{11}$ This reaction involves the combined reduction of the carbonyl group in $\mathrm{C} 1$ position and the oxidation of the adjacent alcohol through a 1,2-intramolecular hydride shift in the ring-opened glucose chain mediated by the tetrahedral Lewis acid position of the framework. ${ }^{12}$

In contrast, the glucose epimerization reaction to mannose has received less attention despite many rare sugars, as it is the case of mannose, are key molecules in the design of antiviral drugs, lowcalorie sweeteners, anti-inflammatory agents or chiral building blocks, among other applications. ${ }^{13}$ Cellobiose 2-epimerase is able to catalyze the $\mathrm{C} 2$-epimerization of glucose to produce mannose, ${ }^{14}$ but the drawbacks associated to the use of enzymes as catalysts, such as temperature and $\mathrm{pH}$ restrictions, limit their application at an industrial scale. In the search for heterogeneous catalysts able to perform the epimerization of glucose, several inorganic solids including Sn-Beta, ${ }^{15}$ molybdenum-based ${ }^{16-18}$ and hydrotalcitetype ${ }^{19}$ materials have been recently reported. ${ }^{20}$ Focusing on Lewisacid containing Sn-Beta zeolite, Davis et al. demonstrated that it is 
possible to modulate the selectivity towards fructose or mannose by modifying the environment or the nature of the active sites in this material. Thus, Sn-Beta is able to facilitate the epimerization of glucose to mannose when using methanol as reaction solvent and, although the mechanistic origins this effect remains unclear, the authors demonstrated that this transformation occurs through the Bilik reaction, which consists in a 1,2-intramolecular carbon shift. ${ }^{15}$ On the other hand, and regarding the nature of the active sites, Davis et al. reported that alkali-free Sn-Beta zeolite favors the fructose production in aqueous media via isomerization, whereas Na-exchanged Sn-Beta zeolite facilitates the epimerization process towards mannose. ${ }^{21}$ Subsequent DFT studies proposed that sodium cations within Sn-Beta stabilize the 1,2-intramolecular carbon shift instead of the 1,2-intramolecular hydride shift mechanism by electrostatic interactions. ${ }^{22}$

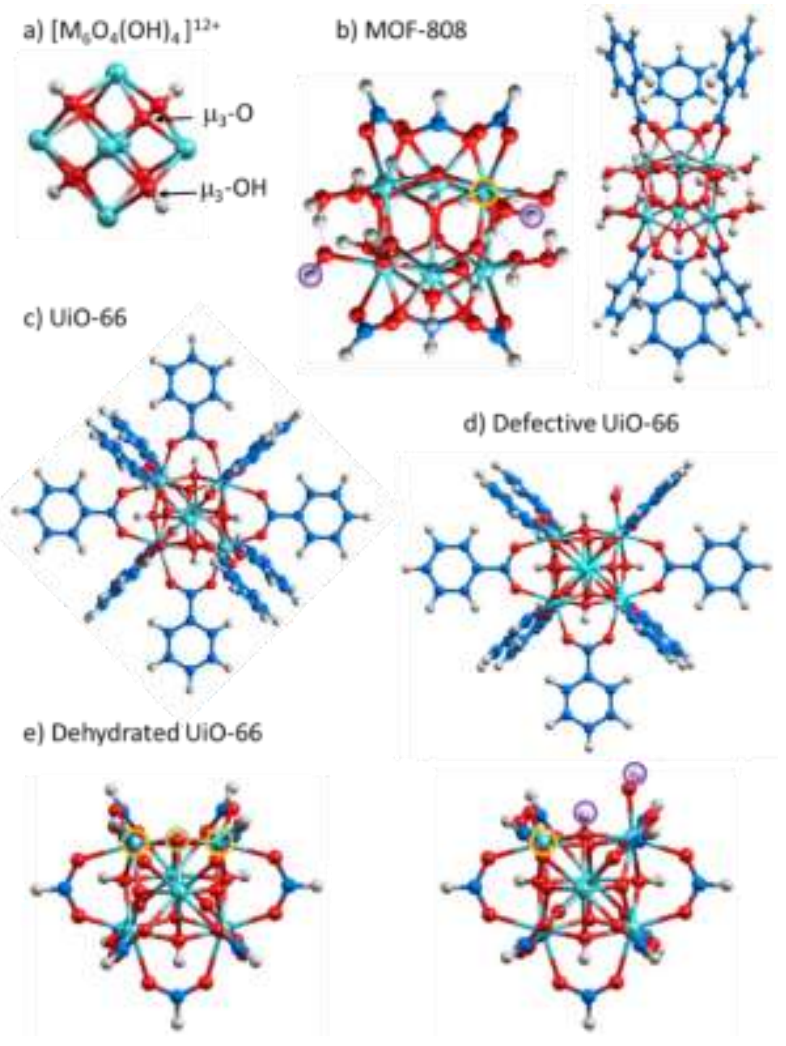

Figure 1. Optimized structures of the $\mathrm{M}_{6} \mathrm{O}_{4}(\mathrm{OH})_{4}$ node (a) and the MOF-808 (b) and UiO-66 (c-e) catalyst models used in this work. $\mathrm{Zr}, \mathrm{O}, \mathrm{C}$ and $\mathrm{H}$ atoms are depicted in cyan, red, blue and white. Yellow, purple and green circles highlight metallic Lewis acid sites, Brønsted acid sites and basic sites, respectively.

Metal-organic frameworks (MOFs) are hybrid microporous crystalline materials formed by metal ions or clusters coordinated by organic ligands. ${ }^{23}$ The large and diverse number of organic linkers and metal nodes that can be employed in the synthesis of MOFs allows modifying their physico-chemical properties and, thus, adapting them to be more active and stable for target catalytic applications. ${ }^{24}$ In particular, $\mathrm{Zr}$ - and Hf-MOFs contain Lewis acid sites whose nature and environment could be modified through the organic linkers to finely modulate their catalytic performance. They have demonstrated high chemical, thermal, and mechanical stability, and as such they have been employed recently in organic transformations of carbonyl-containing molecules derived from biomass for the production of perfumes, flavors and fuelprecursors, ${ }^{25}$ and for cross-aldol condensation reactions even in the presence of quantitative amounts of water and organic acids. ${ }^{26}$

A few studies have evaluated the catalytic activity of other MOFs, i.e. MIL-101(Cr) and ZIF-8(Zn), for the glucose isomerization. ${ }^{27,28}$ The main goal of these researches was the improvement of the MOFs-properties (via metal cluster or organic ligand) to be applied for the one-pot synthesis of HMF from glucose. ${ }^{29-31} \mathrm{Zr}$-containing MOFs UiO-66(Zr) and Zr-MOF-808 have been tested for this onepot transformation using dimethylsulfoxide as solvent, obtaining moderated HMF yields ( 21 and $31 \%$, respectively), probably due to the weak Brønsted acidity of the hydroxyl groups on metal clusters. ${ }^{32}$ However, they have been described as active materials for Meerwein-Ponndorf-Verley reduction reactions, ${ }^{33}$ and therefore they are good candidates to study the glucose transformation reactions in water. Indeed, the catalytic performance of $\mathrm{UiO}-66(\mathrm{Zr})$ and MIL-101(Cr) in aqueous glucose solutions has been studied recently, and different selectivity towards fructose and mannose has been reported. ${ }^{34} \mathrm{MIL}-101(\mathrm{Cr})$ gives preferentially fructose as single product while UiO-66( $\mathrm{Zr})$ produces equimolar quantities of fructose and mannose. The different selectivity was attributed to the different atomic radius of $\mathrm{Cr}$ and $\mathrm{Zr}$ that could result in a stronger electronegativity for the oxygen atoms adjacent to $\mathrm{Zr}$ favoring the epimerization reaction. However, additional fundamental and mechanistic studies are required to properly understand the structure-activity relationship of Zr-MOF materials in the transformation of glucose.

Herein, we have studied two different Lewis acid containing MOFs, Zr-MOF-808 and UiO-66(Zr), for the transformation of glucose in water. Kinetic studies performed for $\mathrm{Zr}-\mathrm{MOF}-808$ and UiO-66(Zr) reveal that the activation barriers to undergo the epimerization reaction are lower than those required for isomerization. To corroborate that the epimerization reaction is occurring in these $\mathrm{Zr}-\mathrm{MOF}$ type-catalysts via 1,2-intramolecular carbon shift (Bilik reaction), ${ }^{13} \mathrm{C}$ NMR studies have been performed using ${ }^{13} \mathrm{C} 1$-labelled glucose, and the key steps of the isomerization and epimerization reaction mechanisms have been computationally investigated. NMR and IR spectroscopic techniques using probe molecules combined with theoretical calculations allow proposing a structure-activity relationship between the different Lewis acid sites present in $\mathrm{Zr}-\mathrm{MOF}$ and $\mathrm{Zr}$ Beta catalysts and the glucose transformation reactions.

\section{RESULTS AND DISCUSSION}

Synthesis and characterization of $\mathrm{Zr}$-based MOFs

Table 1. Physico-chemical properties of the different Zr-MOF materials.

\begin{tabular}{|c|c|c|c|c|c|c|c|}
\hline Sample & $\begin{array}{l}\text { Metal a }^{a} \\
(\% w t)\end{array}$ & $\begin{array}{c}C^{b} \\
(\% w t)\end{array}$ & $\begin{array}{c}\mathbf{H}^{\mathrm{b}} \\
(\% \mathrm{wt})\end{array}$ & $\begin{array}{l}N^{b} \\
(\% w t)\end{array}$ & $\begin{array}{l}\text { BET suf. area } \\
\qquad\left(\mathrm{m}^{2} / \mathrm{g}\right)\end{array}$ & $\begin{array}{l}\text { Microp. area } \\
\qquad\left(\mathrm{m}^{2} / \mathrm{g}\right)\end{array}$ & $\begin{array}{l}\text { Microp. Vol. } \\
\quad\left(\mathrm{cm}^{3} / \mathrm{g}\right)\end{array}$ \\
\hline Zr-MOF-808 & 31.1 & 20.7 & 1.6 & 0.6 & 1531 & 1482 & 0.72 \\
\hline UiO-66(Zr) & 29.3 & 29.3 & 1.6 & 0.5 & 1374 & 1370 & 0.67 \\
\hline
\end{tabular}

\footnotetext{
${ }^{a}$ Measured by ICP analysis
}

${ }^{\mathrm{b}}$ Measured by elemental analvsis 
Both Zr-containing MOF-808 and UiO-66 are based on the same hexaoxometallic node $\left[\mathrm{M}_{6} \mathrm{O}_{4}(\mathrm{OH})_{4}\right]^{12+}$ (Figure 1a), but their connectivity with the negatively charged organic linkers containing carboxylate groups and the resulting crystalline structure are different. UiO-66( $\mathrm{Zr})$ presents a 12-connectivity on the metal cluster, and the reported pore sizes are between 8 and $11 \AA .{ }^{35}$ In perfect UiO-66(Zr) crystals all the metal atoms of the cluster are fully coordinated and therefore not accessible to reactants (Figure 1c), but the presence of missing linker defects creates accessible metallic Lewis acid active sites (Figure 1d). On the other hand, $\mathrm{Zr}$ MOF-808 has a 6-connectivity on the metal cluster, which is lower than UiO-66(Zr), suggesting an easier accessibility of the reactants to the metallic active sites(Figure 1b). ${ }^{36}$ The excess positive charge in the nodes of $\mathrm{Zr}$-MOF-808 is compensated by hydroxyl groups and coordinated water molecules. Moreover, Zr-MOF-808 structures show adamantane-type apertures, which results in pore windows of $\sim 18.4 \AA,{ }^{37}$ which are considerably higher than those observed within the UiO-66(Zr) structure.

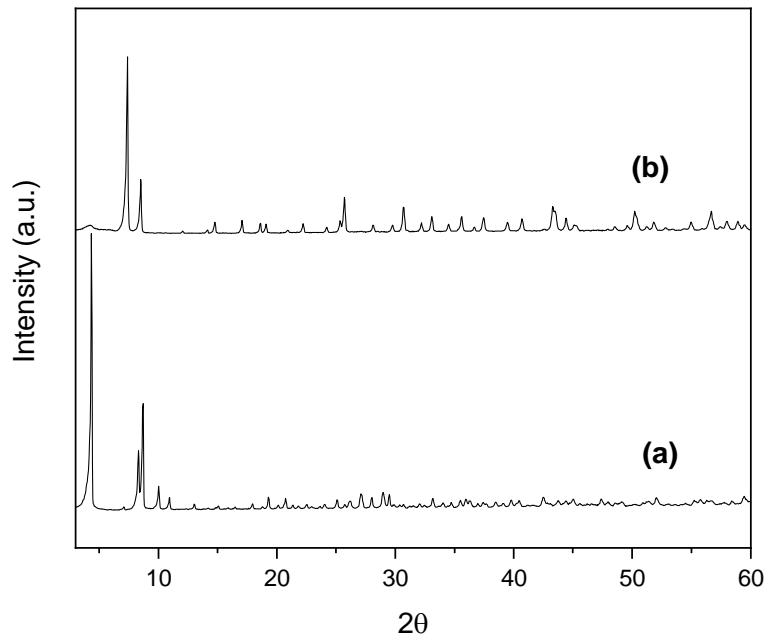

Figure 2. PXRD patterns of Zr-MOF-808 (a) and UiO-66(Zr) (b).

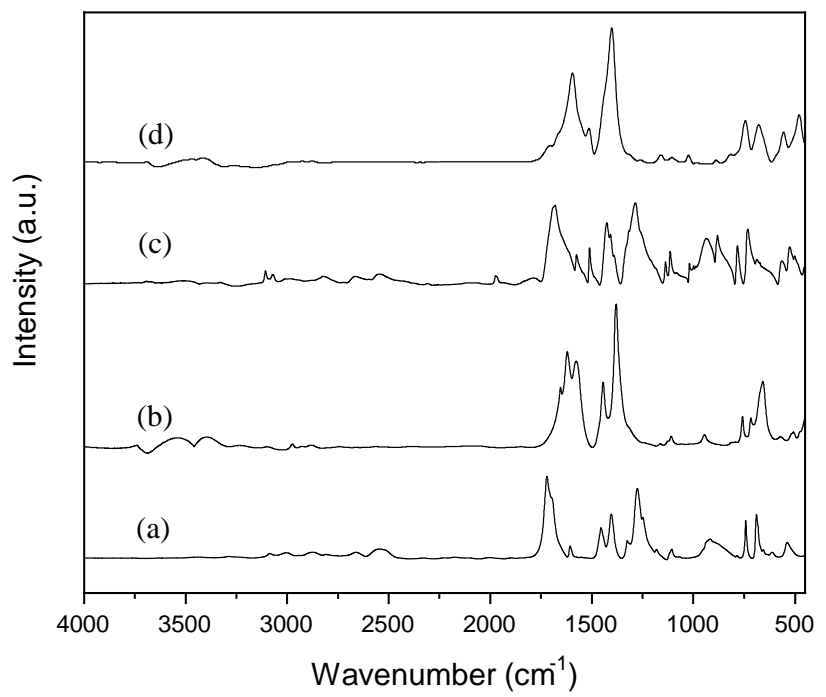

Figure 3. FTIR spectra of the Zr-MOF-808 (b) and UiO-66(Zr) (d) materials together with the FTIR spectra of the organic ligands (a) and (c) employed in their particular preparation.

The Lewis-acid containing UiO-66(Zr) and Zr-MOF-808 were synthesized following previous reports in the literature (see experimental section for details). ${ }^{38,39}$ The resultant solids show the characteristic PXRD patterns of the UiO-66(Zr) and Zr-MOF-808 materials (see Figure 2), indicating that these materials show highcrystallinity. $\mathrm{N}_{2}$ adsorption characterization shows the microporosity of the synthesized Zr-MOF-808 and UiO-66(Zr) materials, yielding high micropore areas (between $\sim 1300$ and $\sim 1500 \mathrm{~m}^{2} / \mathrm{g}$, see Table 1$)$ and micropore volumes $\left(\sim 0.70 \mathrm{~cm}^{3} / \mathrm{g}\right.$, see Table 1). Moreover, the characterization of the different MOFs by FTIR spectroscopy clearly shows the disappearance of the signal centered at $\sim 1700 \mathrm{~cm}^{-1}$ (see Figure 3), which corresponds with the carboxylic acid group of the organic ligands, suggesting the entire interaction of the organic ligands with the metal clusters.
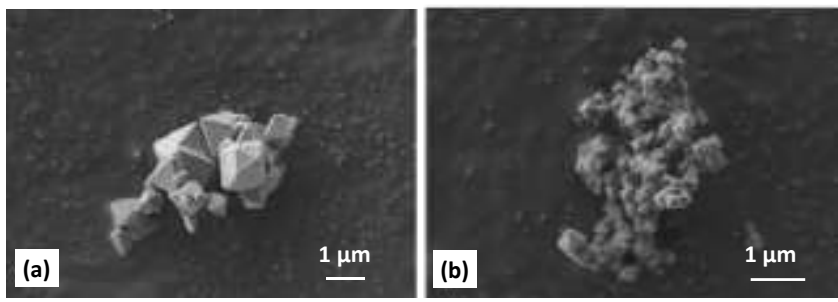

Figure 4. FE-SEM images of Zr-MOF-808 (a) UiO-66(Zr) (b).

Finally, the different solids have been studied by field emission scanning electron microscopy (FESEM) to evaluate their crystal morphology. As seen in Figure 4, octahedral crystals can be observed for both type of MOFs, detecting smaller particle sizes for UiO-66(Zr) samples ( 200-400 nm) than for Zr-MOF-808 samples ( 400-800 nm).

Kinetic studies for glucose transformations using $\mathrm{Zr}$-based MOFs as catalysts

Kinetic studies were performed at different temperatures $(90,110$, 125 and $140^{\circ} \mathrm{C}$ ) using $\mathrm{Zr}-\mathrm{MOF}-808$ and $\mathrm{UiO}-66(\mathrm{Zr})$ catalysts for glucose transformations in water (glucose:metal molar ratio of 25). Figure 5 summarizes the kinetic profiles for the glucose transformation reactions in water at different temperatures using Zr-MOF-808 (Figure 5-left) and UiO-66(Zr) (Figure 5-right). There, glucose conversion together with mannose and fructose concentrations have been plotted as a function of reaction time. It can be stated from the kinetic curves that the ratio of mannose to fructose is larger for $\mathrm{UiO}-66(\mathrm{Zr})$ than for $\mathrm{Zr}-\mathrm{MOF}-808$. It is also observed that the mannose/fructose ratio shows its maximum value at low temperatures [see $\mathrm{UiO}-66(\mathrm{Zr})-90^{\circ} \mathrm{C}$ in Figure 5].

The fact that fructose and mannose are formed from the first moment the reaction starts (non-zero initial rate) would indicate that both are primary products and, consequently, glucose isomerization and epimerization reactions are occurring in parallel within the MOF-type catalysts. Then, considering a pseudo-firstorder dependence for both reactions (see experimental conditions for details), the kinetic rate constants for isomerization and epimerization ( $k_{\text {isom }, F}$ and $k_{\text {epim, }, M}$, respectively) have been calculated from initial reaction rates (see Table 2). The $k_{\text {epim, }} / k_{\text {isom }, F}$ ratios are 1.5-2 higher on UiO-66( $\mathrm{Zr})$ than on $\mathrm{Zr}-\mathrm{MOF}-808$ regardless the reaction temperature (see Table 2 ), clearly evidencing the improved ability of UiO-66( $\mathrm{Zr})$ to facilitate the epimerization pathway over the isomerization mechanism.

The apparent activation energies for the glucose isomerization and epimerization reactions were calculated from the linearized Arrhenius equation, and the values obtained on $\mathrm{Zr}-\mathrm{MOF}-808$ were $E_{a, \text { isom }}=100 \mathrm{~kJ} / \mathrm{mol}$ and $E_{a, \text { epim }}=88 \mathrm{~kJ} / \mathrm{mol}$, while on $\mathrm{UiO}-66(\mathrm{Zr})$ were $E_{a, \text { isom }}=101 \mathrm{~kJ} / \mathrm{mol}$ and $E_{a, \text { epim }}=83 \mathrm{~kJ} / \mathrm{mol}$ (see Figure 6). These data indicate that the experimental activation energies for glucose epimerization are lower than those for glucose isomerization on both MOF catalysts. Moreover, the apparent activation energy for the epimerization pathway is lower on $\mathrm{UiO}-66(\mathrm{Zr})$ than in $\mathrm{Zr}$ - 
MOF-808 (83 and $88 \mathrm{~kJ} / \mathrm{mol}$, respectively, see Figure 6). Thus, taking into account that both MOF catalysts present analogous activation barrier for glucose isomerization, the lower activation energy of $\mathrm{UiO}-66(\mathrm{Zr})$ for glucose epimerization compared to $\mathrm{Zr}$ MOF-808 would explain the higher values observed for the mannose/fructose ratios with $\mathrm{UiO}-66(\mathrm{Zr})$.
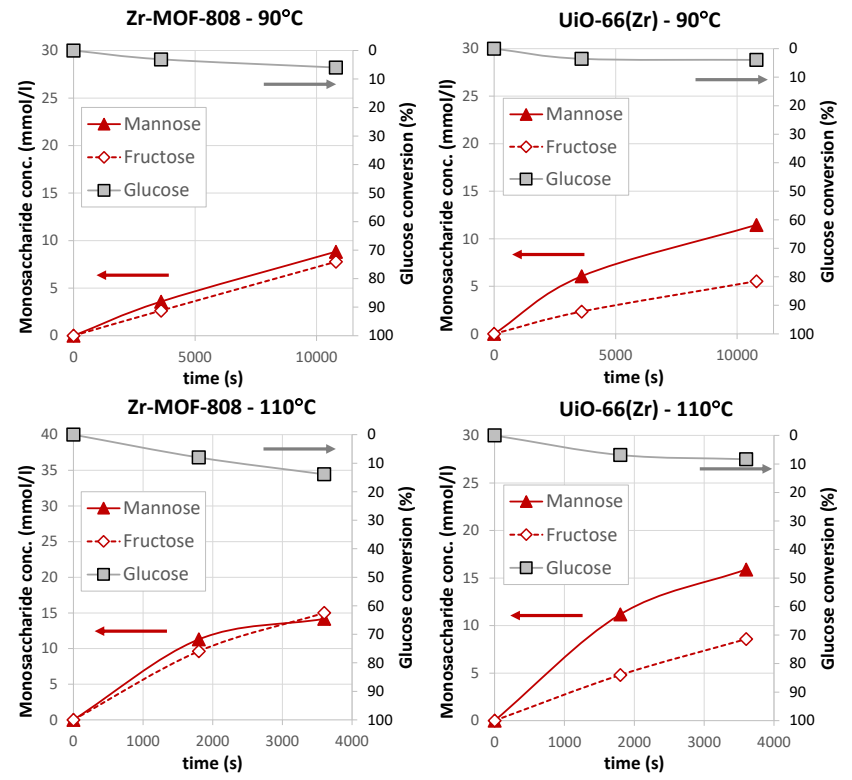

Zr-MOF- $808-125^{\circ} \mathrm{C}$
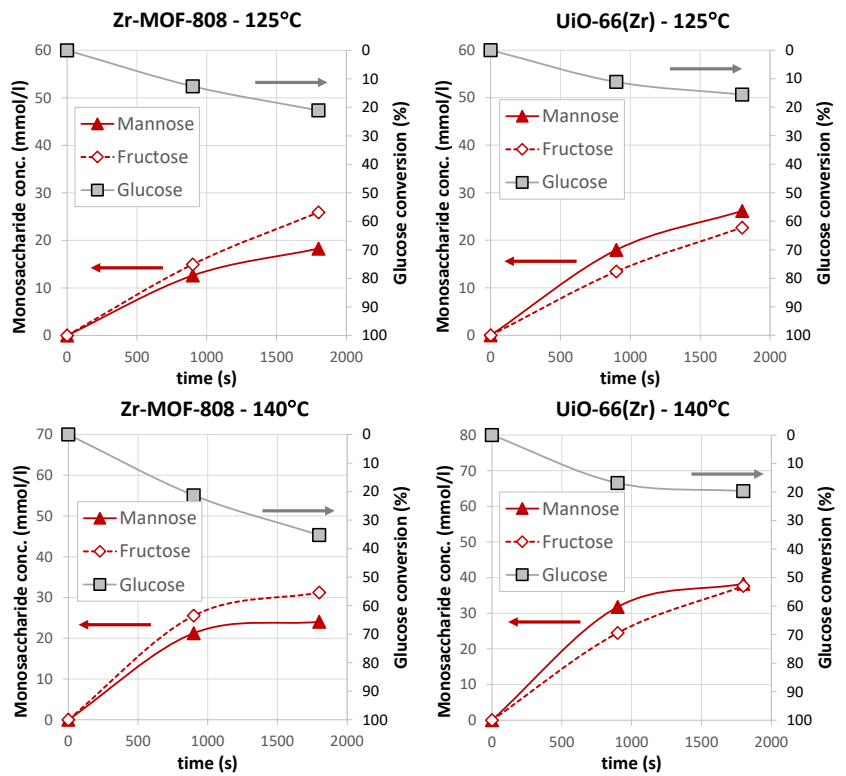

Figure 5. Kinetic profiles with glucose conversion (grey squares) and product concentrations (mannose: red triangles, fructose: empty diamonds) achieved at different temperatures (90, 110, 125 and $140^{\circ} \mathrm{C}$ ) using as catalysts the $\mathrm{Zr}-\mathrm{MOF}-808$ and UiO-66( $\left.\mathrm{Zr}\right)$. Reaction conditions: $10 \mathrm{wt} \%$ glucose aqueous solutions with a glucose:metal molar ratio of 25:1.

Comparison of these calculated values with other apparent activation barriers reported in the literature using other catalytic systems evidences that the $E_{a, e p i m}$ achieved here for the MOF-type catalysts are lower than those reported for glucose epimerization using molybdate catalysts $(126 \mathrm{~kJ} / \mathrm{mol}$ for ammonium heptamolybdate ${ }^{40}$ and $97 \mathrm{~kJ} / \mathrm{mol}$ for molybdenum-based polyoxometalates ${ }^{41}$ ) and that the $E_{a, \text { isom }}$ values are similar for the glucose isomerization catalyzed by Sn-Beta $(93 \mathrm{~kJ} / \mathrm{mol}) .{ }^{15,42}$
Table 2. Measured pseudo-first-order rate constants at different temperatures for glucose-fructose isomerization $\left(k_{\text {isom }, F}\right)$ and glucose-mannose epimerization $\left(k_{\text {epim, }}\right.$ ) on $\mathrm{Zr}-\mathrm{MOF}-808$ and UiO66(Zr).

\begin{tabular}{ccccc}
\hline Catalyst & $\begin{array}{c}\mathbf{T} \\
\left({ }^{\mathbf{C}} \mathbf{C}\right)\end{array}$ & $\boldsymbol{k}_{\text {isom, } \boldsymbol{F} \cdot \mathbf{1 0}^{\mathbf{6}}}$ & $\boldsymbol{k}_{\text {epim }, \boldsymbol{M} \cdot \mathbf{1 0}^{\mathbf{6}}}$ & \\
\hline & 90 & 2.8 & 3.2 & 1.2 \\
\hline \multirow{2}{*}{ Zr-MOF-808 } & 110 & 21.0 & 21.5 & 1.0 \\
& 125 & 77.5 & 57.7 & 0.8 \\
& 140 & 137.2 & 109.2 & 0.8 \\
\hline \multirow{2}{*}{ UiO-66(Zr) } & 110 & 9.1 & 3.0 & 2.2 \\
& 90 & 1.4 & 18.1 & 2.0 \\
& 125 & 46.0 & 55.6 & 1.2 \\
& 140 & 65.4 & 72.9 & 1.1 \\
\hline
\end{tabular}

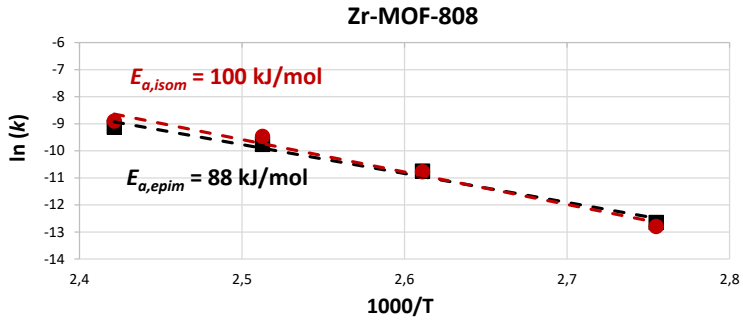

Uio-66(Zr)

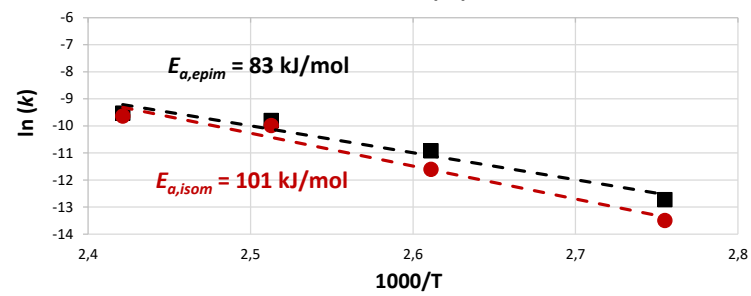

Figure 6. Temperature dependence (X-axis) of the kinetic catalysts constants (Y-axis) for glucose isomerization to fructose (red circles) and epimerization to mannose (black squares). The calculated apparent activation energies for glucose isomerization and epimerization reactions are included in the figure. The estimated errors for the $E_{a}$ values are $\pm 5 \mathrm{~kJ} / \mathrm{mol}$.

\section{Reaction mechanism study using ${ }^{13} \mathrm{C}$ NMR spectroscopy and isotopically labeled glucose}

Sn-Beta has been extensively employed in the literature as an efficient catalyst for the glucose isomerization reaction in aqueous conditions. ${ }^{11,12}$ However, considering that in the present work the catalytic behavior of different $\mathrm{Zr}$-containing MOFs has been evaluated, a Zr-Beta zeolite has been proposed to properly assess the mechanistic differences between an isomorphically metalsubstituted zeolite and the $\mathrm{Zr}$-containing MOFs (see experimental section for details). Figure 7 summarizes the glucose conversion values obtained using these materials as a function of reaction time together with the achieved fructose/mannose molar ratios, where the experiments were performed at $90^{\circ} \mathrm{C}$. Interestingly, under similar glucose conversion levels for the different $\mathrm{Zr}$-containing materials, it is clearly observed that $\mathrm{Zr}$-Beta shows the highest fructose/mannose ratio $(\sim 5)$, while $\mathrm{UiO}-66(\mathrm{Zr})$ gives the lowest 
fructose/mannose ratio ( $\sim 0.3)$, clearly suggesting different glucose transformation pathways for them.

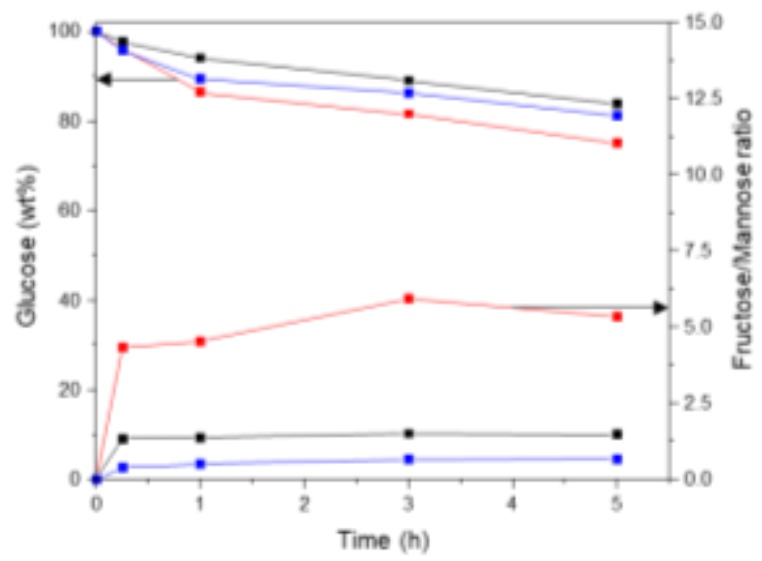

Figure 7. Kinetic profiles for glucose conversion (left $\mathrm{Y}$-axis) and fructose/mannose molar ratio (right $\mathrm{Y}$-axis) employing $\mathrm{Zr}$-Beta (red line), Zr-MOF-808 (black line) and UiO-66(Zr) (blue line) as catalysts. Reaction conditions: $10 \mathrm{wt} \%$ glucose aqueous solutions at $90^{\circ} \mathrm{C}$, glucose/metal ratios of 50 and 12 for $\mathrm{Zr}$-Beta and $\mathrm{Zr}$ MOFs, respectively, to facilitate similar glucose conversions for all materials.
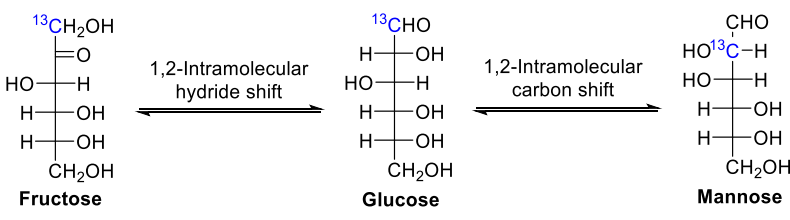

Figure 8. Proposed routes for ${ }^{13} \mathrm{C}-\mathrm{C} 1$-glucose epimerization and isomerization reactions that involves 1,2-intramolecular carbon or hydride shift, respectively.

${ }^{13} \mathrm{C}$ NMR studies were conducted to gain insight into the mechanism of the glucose isomerization and epimerization reactions (see Figure 8 ). For these experiments, $1 \%$ wt ${ }^{13} \mathrm{C}-\mathrm{C} 1-$ glucose solutions were employed as starting solutions using the different $\mathrm{Zr}$-containing catalysts. Reactions were performed during $2 \mathrm{~h}$ at $90^{\circ} \mathrm{C}$, then quenched and filtered and, finally, measured by ${ }^{13} \mathrm{C}$ NMR spectroscopy. The ${ }^{13} \mathrm{C}$ NMR spectrum of the blank experiment made without catalyst only shows the signals centered at 96.0 and $92.2 \mathrm{ppm}$, which correspond to the ${ }^{13} \mathrm{C}-\mathrm{C} 1$ enriched $\mathrm{D}$ glucose (see Figure 9). The ${ }^{13} \mathrm{C}$ NMR spectra of the experiments performed using the $\mathrm{Zr}$-containing catalysts show all of them the appearance of resonances at 64.0 and $62.8 \mathrm{ppm}$, which correspond to the $\beta$-pyranose and $\beta$-furanose fructose conformers that are formed through the isomerization reaction by 1,2-intramolecular hydride shift [see Zr-Beta, Zr-MOF-808 and UiO-66(Zr) in Figures $9 \mathrm{~b}, 9 \mathrm{c}$ and $9 \mathrm{~d}$, respectively]. ${ }^{43}$ However, other signals centered at 71.3 and $70.8 \mathrm{ppm}$ were detected in the ${ }^{13} \mathrm{C}$ spectra of the Zr-MOF808 and UiO-66( $\mathrm{Zr})$ (see Figures 9c and 9d, respectively), which are associated with $\alpha$ - and $\beta$-pyranose conformers of mannose with the ${ }^{13} \mathrm{C}$ labelled in $\mathrm{C} 2$ position, indicating that mannose in $\mathrm{Zr}-\mathrm{MOF}$ catalysts is exclusively produced through 1,2-intramolecular carbon shift. Thus, these results allow concluding that mannose is formed in $\mathrm{Zr}$-MOFs via epimerization following the so-called Bilik reaction pathway, ${ }^{44}$ whereas the mannose generated on $\mathrm{Zr}$-Beta is produced preferentially through a consecutive isomerization of fructose.
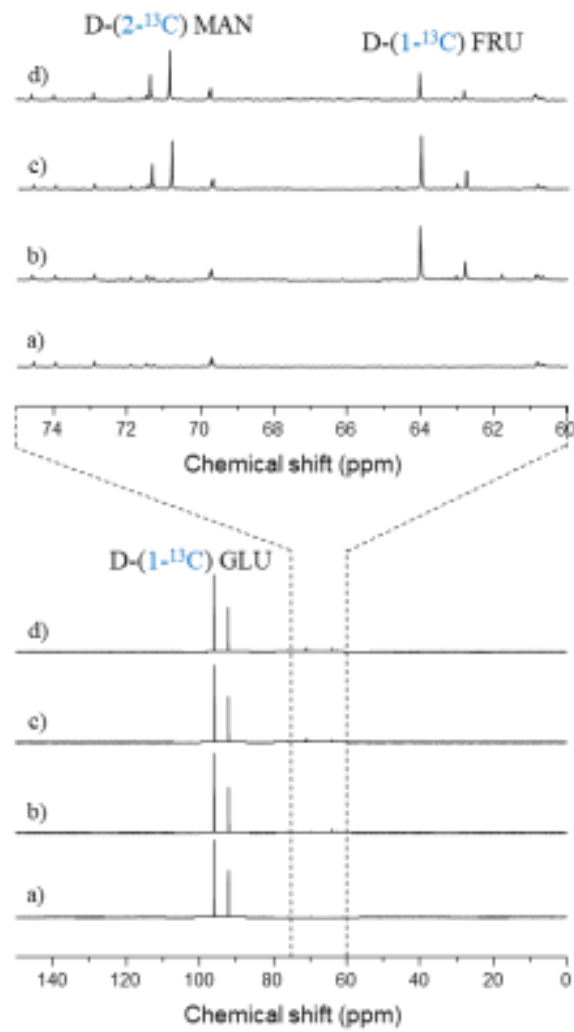

Figure 9. ${ }^{13} \mathrm{C}$ NMR spectra of the resulting reaction mixtures with a) no catalyst, b) Zr-Beta, c) Zr-MOF-808 and d) UiO-66(Zr). Reaction conditions: $1 \mathrm{wt} \%{ }^{13} \mathrm{C}-\mathrm{C} 1$-glucose aqueous solution at $363 \mathrm{~K}$ for $2 \mathrm{~h}$.

Nature of the Lewis acid active sites in $\mathrm{Zr}$-MOFs

To evaluate the nature of the Lewis acid active sites in the catalysts tested, the $\mathrm{Zr}$ environment in $\mathrm{Zr}-\mathrm{MOF}-808$, UiO-66(Zr) and $\mathrm{Zr}$ Beta zeolite was studied using ${ }^{31} \mathrm{P}$ NMR spectroscopy after adsorbing trimethylphosphine oxide (TMPO) as probe molecule, a technique that has been successfully employed to distinguish active sites into different materials. ${ }^{45}$ For example, TMPO adsorbed on different metal-substituted Beta-zeolites allowed to correlate the different Lewis acid sites with the catalytic activity for glucose isomerization and cross-aldol condensation. ${ }^{46}$ According to this previous work, TMPO was adsorbed in $\mathrm{Zr}-\mathrm{MOF}-808$ and $\mathrm{UiO}-$ 66( $\mathrm{Zr})$ materials, as well as in $\mathrm{Zr}$-Beta zeolite for comparison purposes (see experimental section for details), and the $\delta_{\text {iso }}\left({ }^{31} \mathrm{P}\right)$ chemical shifts of TMPO interacting with $\mathrm{Zr}$-Beta and with models of $\mathrm{Zr}-\mathrm{MOF}-808$ and $\mathrm{UiO}-66(\mathrm{Zr})$ containing benzoate ligands was simulated by means of DFT calculations.

The ${ }^{31} \mathrm{P}$ MAS NMR spectrum of the TMPO-containing Zr-Beta (Figure 10a) shows three well-defined characteristic signals at 55, 57 and $61 \mathrm{ppm}$, which have been assigned to the interaction of the TMPO molecules with the isolated Lewis acid sites in the zeolitic framework. ${ }^{46}$ In agreement with this assignment, the chemical shifts obtained from DFT calculations for TMPO interacting with open- and closed-sites in Zr-Beta appear between 56 and 62 ppm, depending on the location of the $\mathrm{Zr}$ atom (see Table S2 and Figure $\mathrm{S} 1)$. In the case of both MOFs, the resonances appearing at $\sim 55-57$ ppm due to the Lewis acid-TMPO interaction are also present in the ${ }^{31} \mathrm{P}$ NMR spectra (see Figures $10 \mathrm{~b}$ and $10 \mathrm{c}$ ), but the peaks show less resolution, especially in MOF-808. This is probably due to the heterogeneity of the interactions of TMPO with the $\mathrm{Zr}$ sites in MOF-808, where several $\mathrm{Zr}$ centers are accessible in each node. 


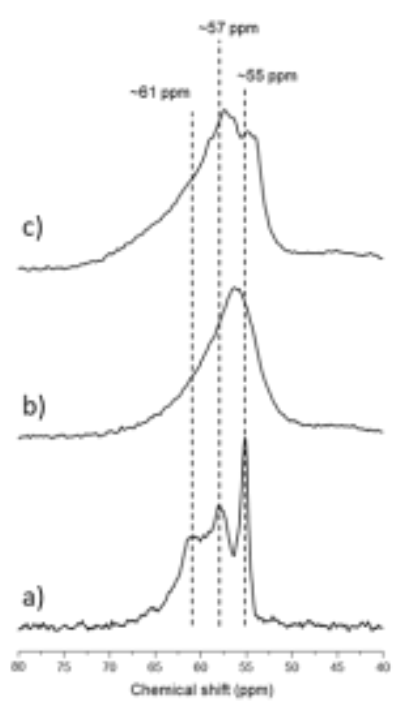

Figure 10. ${ }^{31} \mathrm{P}$ MAS NMR spectra of TMPO-containing Zr-Beta (a), Zr-MOF-808 (b) and UiO-66(Zr) (c).

The $\delta_{\text {iso }}\left({ }^{31} \mathrm{P}\right)$ chemical shifts calculated for just one TMPO molecule interacting with either $\mathrm{UiO}-66(\mathrm{Zr})$ or $\mathrm{Zr}-\mathrm{MOF}-808$ are similar, 52 and $53 \mathrm{ppm}$, respectively, but the presence of a close TMPO molecule interacting with a proximal hydroxyl group in MOF-808 displaces the calculated $\delta_{\text {iso }}\left({ }^{31} \mathrm{P}\right)$ chemical shift for the Zr-bonded TMPO molecule to $59 \mathrm{ppm}$ (see Table S2). Thus, the possible co-adsorption of more than one TMPO molecules on the same $\left[\mathrm{Zr}_{6} \mathrm{O}_{4}(\mathrm{OH})_{4}\right]^{12+}$ node in MOF-808 would explain the better signal resolution achieved on $\mathrm{UiO}-66(\mathrm{Zr})$, where this co-adsorption is less probable. On the other hand, dehydration of the UiO-66(Zr) active site following a model described in the literature ${ }^{47}$ leaves two metal Lewis acid centers and a basic $\mathrm{O}^{2-}$ atom on the hexaoxometal cluster (see Figure 1e), and displaces the calculated $\delta_{\text {iso }}\left({ }^{31} \mathrm{P}\right)$ signal of adsorbed TMPO to $56 \mathrm{ppm}$ (Table S2), in agreement with the signals observed in the recorded NMR spectra (see Figure 10c).

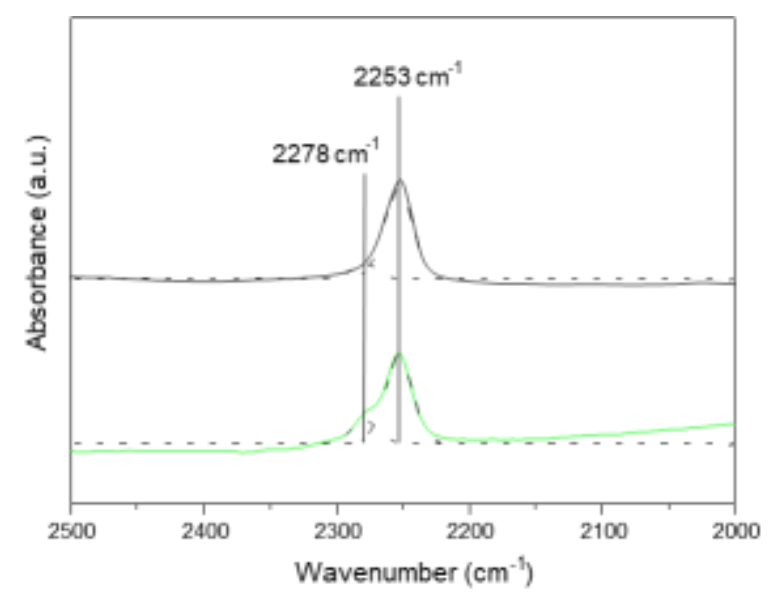

Figure 11. FTIR spectra of adsorbed $\mathrm{CDCl}_{3}$ on $\mathrm{UiO}-66(\mathrm{Zr})$ (green line) and Zr-MOF-808 (black line).

To confirm the presence of basic centers in the MOF structures and identify their nature, $\mathrm{Zr}-\mathrm{MOF}-808$ and $\mathrm{UiO}-66(\mathrm{Zr})$ were studied by FTIR spectroscopy using $\mathrm{CDCl}_{3}$ as weak acid probe molecule (see Figure 11). It has been reported that the signal at $2253 \mathrm{~cm}^{-1}$ corresponds to $\mathrm{CDCl}_{3}$ interacting with basic sites formed by the carboxylic group in the MOF skeleton interacting with the metal cluster. ${ }^{48}$ However, an additional signal at $2278 \mathrm{~cm}^{-1}$ is present in the FTIR spectra after adsorbing $\mathrm{CDCl}_{3}$, indicating that there is an additional basic site, which has been tentatively assigned to $\mathrm{O}^{2-}$ species in the metallic hexaoxocluster. ${ }^{26}$ The intensity of this band is considerably higher in UiO-66( $\mathrm{Zr}$ ) than in $\mathrm{Zr}-\mathrm{MOF}-808$, in agreement with the assignment of the ${ }^{31} \mathrm{P}$ NMR spectra of UiO66( $\mathrm{Zr})$ and $\mathrm{Zr}-\mathrm{MOF}-808$. However, although these basic $\mathrm{O}^{2-}$ species are spectroscopically observed in dehydrated samples of UiO-66(Zr), they will probably re-hydrate readily in the presence of water producing surface hydroxyl groups that will participate in the initial deprotonation of glucose.

Table 3. DFT calculated activation energies for the H-shift and Cshift steps leading to isomerization and epimerization of glucose on Zr-Beta, Zr-UiO-66 and Zr-MOF-808 catalyst models.

\begin{tabular}{ccc} 
Sample & $\boldsymbol{E}_{\boldsymbol{a} \text {,isom }}(\mathbf{k J} / \mathbf{m o l})$ & $\boldsymbol{E}_{\boldsymbol{a}, \text { epim }}(\mathbf{k J} / \mathbf{m o l})$ \\
\hline Zr-Beta & 86.9 & 138.1 \\
UiO-66(Zr) & 96.5 & 82.9 \\
Zr-MOF-808-A & 99.9 & 78.1 \\
Zr-MOF-808-B & 80.6 & 108.6 \\
\hline
\end{tabular}

Computational study of the reaction mechanism in Zr-MOFs and $\mathrm{Zr}$-Beta catalysts

To provide a better understanding at the molecular level of the mechanistic differences between $\mathrm{Zr}$-Beta zeolite and $\mathrm{Zr}$-containing MOFs in the transformation of glucose, a computational study of the key steps of the isomerization and epimerization reaction pathways was performed using cluster models of Zr-MOF-808, UiO-66(Zr) and Zr-Beta catalysts (see Figures 1 and 12). The models employed to simulate the $\mathrm{Zr}$-MOFs consist of one $\left[\mathrm{Zr}_{6} \mathrm{O}_{4}(\mathrm{OH})_{4}\right]^{12+}$ node surrounded by the corresponding number of formiate ligands, charge-compensating hydroxyl groups and additional stabilizing water molecules (see experimental section for computational details), while the model for $\mathrm{Zr}$-Beta zeolite was cut out from the periodic crystalline structure and contains one framework $\mathrm{Zr}$ atom with one hydrolyzed $\mathrm{Zr}-\mathrm{OH}$ bond (open-site, see Figure 12).

According to previous mechanistic studies of glucose transformation on Sn-Beta catalysts, ${ }^{22,43}$ the first step of the reaction is the ring-opening of glucose and its deprotonation assisted by a hydroxyl group to form a bidentate complex in which the two $\mathrm{O} 1$ and $\mathrm{O} 2$ atoms of the monosaccharide are bonded to the Lewis acid $\mathrm{Sn}$ center. The same bidentate structure was obtained here on Zr-Beta catalyst (see structure GLU in Figure 12), with the water molecule formed by reaction of the hydroxyl group with the proton of glucose remaining attached to the $\mathrm{Zr}$ center. Starting from this reactant structure labelled GLU, fructose (FRU) and mannose (MAN) are formed by intramolecular 1,2-H shift or 1,2-C shift through transition states TSH and TSC, respectively (see Figure 12 and Table S3). The activation energy calculated for the H-shift step leading to isomerization, $86.9 \mathrm{~kJ} / \mathrm{mol}$, is not too different from the values previously reported for Sn-Beta, ${ }^{22,43}$ and remarkably lower than the activation energy obtained for the epimerization via intramolecular C-shift, $138.1 \mathrm{~kJ} / \mathrm{mol}$ (see Table 3), in agreement with the ${ }^{13} \mathrm{C}$ NMR results showing that mannose is not formed via epimerization in $\mathrm{Zr}$-Beta (see Figure 9). Instead, it is formed from fructose by a second $\mathrm{H}$-shift through TSH2 in Figure 12 with an activation energy of $90.7 \mathrm{~kJ} / \mathrm{mol}$. 


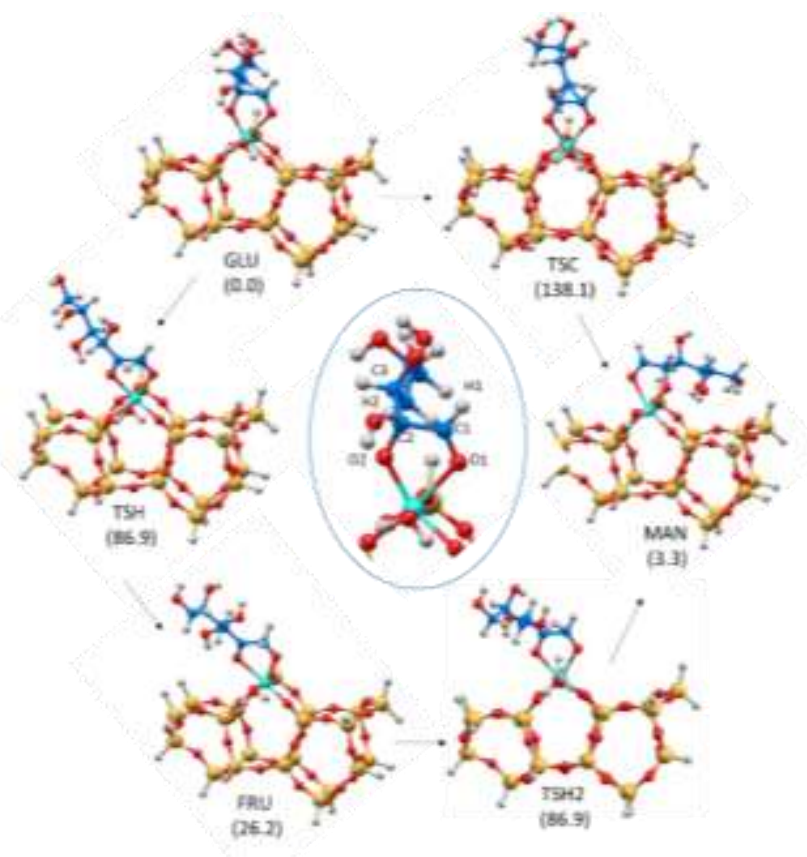

Figure 12. DFT optimized structures of glucose (GLU), fructose (FRU), mannose (MAN) and the transition states for H-shifts (TSH and TSH2) and epimerization (TSC) on Zr-Beta. Relative energies in $\mathrm{kJ} / \mathrm{mol}$ are given in parenthesis. $\mathrm{Zr}, \mathrm{Si}, \mathrm{O}, \mathrm{C}$, and $\mathrm{H}$ atoms are depicted in cyan, yellow, red, blue and white, respectively. The atom labelling scheme is shown on a framed and enlarged image of GLU structure in the centre of the Figure

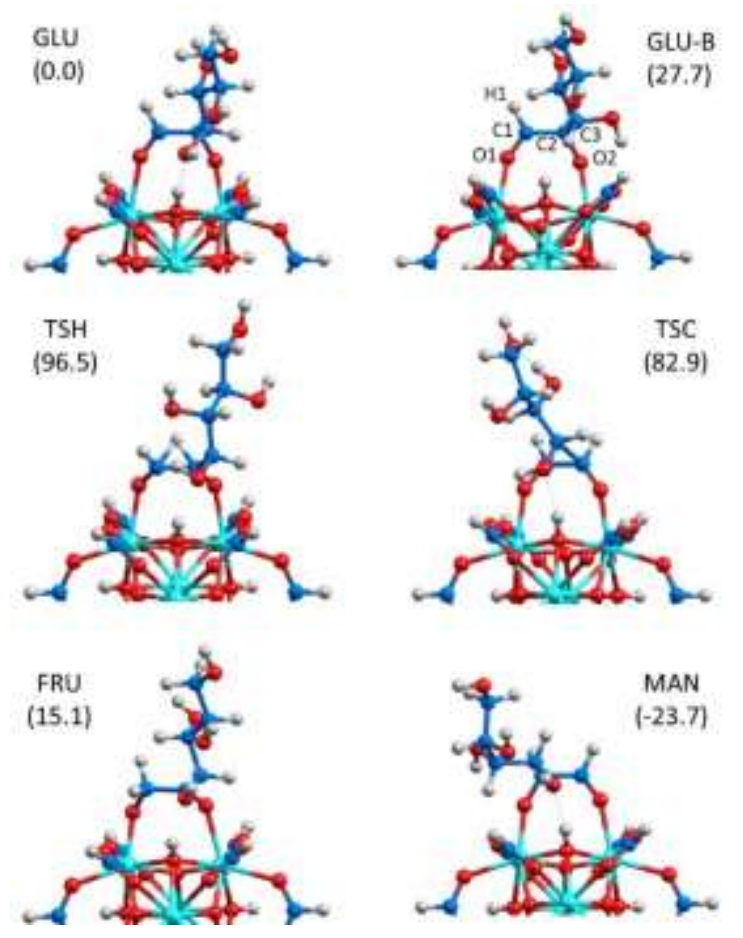

Figure 13. DFT optimized structures of glucose (GLU and GLUB), fructose (FRU), mannose (MAN) and the transition states for isomerization (TSH) and epimerization (TSC) on UiO-66( $\mathrm{Zr}$ ). Relative energies in $\mathrm{kJ} / \mathrm{mol}$ are given in parenthesis. $\mathrm{Zr}, \mathrm{O}, \mathrm{C}$, and $\mathrm{H}$ atoms are depicted in cyan, red, blue and white, respectively. The atom labelling scheme is shown on GLU-B structure.
The nodes of Zr-MOFs also possess hydroxyl groups able to promote the deprotonation of acyclic glucose (see Figure 1). But, in contrast to $\mathrm{Sn}$ - and $\mathrm{Zr}$-Beta catalysts, in the bidentate complexes formed on UiO-66 and MOF-808, each of the two $\mathrm{O} 1$ and $\mathrm{O} 2$ atoms of deprotonated glucose bind to a different $\mathrm{Zr}$ atom (see Figures 13, 14, S2 and S3). In UiO-66(Zr) there are only two accessible $\mathrm{Zr}$ atoms able to make new bonds, and two different orientations for adsorbed glucose. In the most stable conformation (GLU in Figure 13) an extra hydrogen bond is formed between one of the four protons belonging to the $\left[\mathrm{Zr}_{6} \mathrm{O}_{4}(\mathrm{OH})_{4}\right]^{12+}$ node and the $\mathrm{OH}$ group attached to $\mathrm{C} 3$. This hydrogen bond cannot be formed in structure GLU-B, which is consequently $27.7 \mathrm{~kJ} / \mathrm{mol}$ less stable than GLU. In addition, this $\mathrm{H}$ bond is partly broken in transition state TSH leading to fructose but not in TSC producing mannose, which is therefore $13 \mathrm{~kJ} / \mathrm{mol}$ more stable (see Figure 13). A closer analysis of the optimized geometries of all structures in $\mathrm{Zr}$-Beta and UiO66(Zr) (see Tables S3 and S4 in the Supporting Information) shows that the $\mathrm{C} 1-\mathrm{C} 2$ bonds in both transition states are slightly longer in the MOF, while the $\mathrm{C} 1-\mathrm{C} 3$ and $\mathrm{C} 2-\mathrm{C} 3$ distances in TSC are shorter in UiO-66(Zr). The activation energies calculated for the $\mathrm{H}$-shift and C-shift steps on UiO-66(Zr) model are $96.5 \mathrm{~kJ} / \mathrm{mol}$ and 82.9 $\mathrm{kJ} / \mathrm{mol}$, respectively, (see Table 3 ) in good agreement with the apparent activation energies obtained experimentally $\left(E_{a, \text { isom }}=101\right.$ $\mathrm{kJ} / \mathrm{mol}$ and $E_{a, \text { epim }}=83 \mathrm{~kJ} / \mathrm{mol}$, see Figure 6).

To confirm the influence of the adsorption mode of glucose on the selectivity to mannose, and taking into account that the presence of co-adsorbed water in UiO-66(Zr) stabilizes a bidentate complex with the two $\mathrm{O} 1$ and $\mathrm{O} 2$ atoms of deprotonated glucose bonded to the same $\mathrm{Zr}$ atom (structure $\mathrm{GLU}_{1}-\mathrm{H}_{2} \mathrm{O}$ in Figure $\mathrm{S} 3$ ), we calculated the $\mathrm{H}$-shift and C-shift steps starting from $\mathrm{GLU}_{1}-\mathrm{H}_{2} \mathrm{O}$ (see optimized structures in Figure S4). The activation energies calculated for isomerization and epimerization, 142.2 and 147.9 $\mathrm{kJ} / \mathrm{mol}$, respectively, are significantly higher than those obtained starting from GLU, suggesting a lower reactivity of this mode of adsorption.
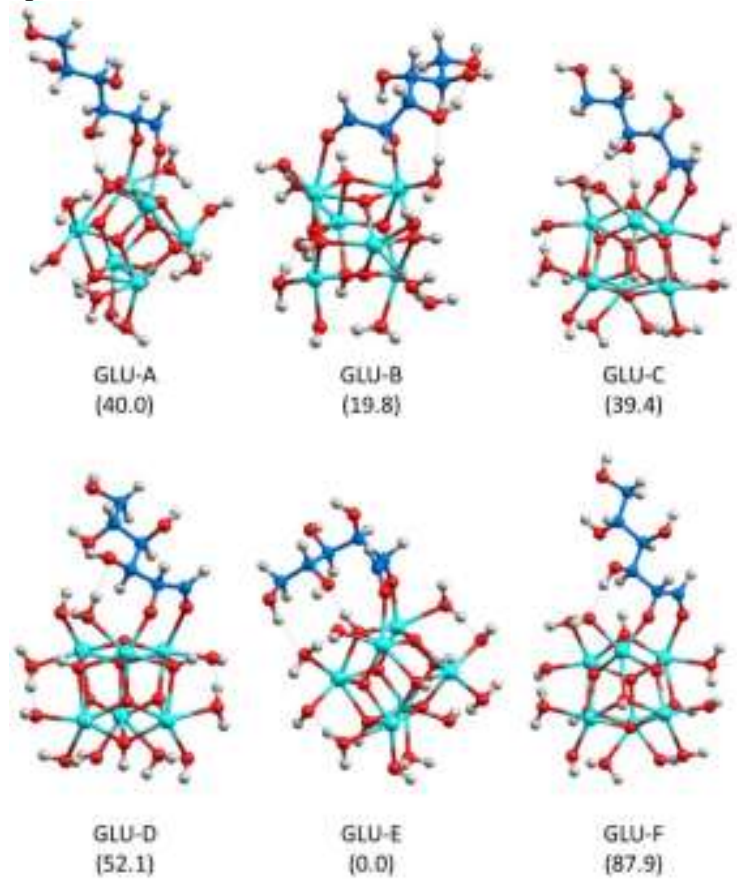

Figure 14. DFT optimized structures of six different orientations for deprotonated glucose on $\mathrm{Zr}-\mathrm{MOF}-808$, with their relative stability in $\mathrm{kJ} / \mathrm{mol}$ given in parenthesis. The organic ligands have been omitted for clarity, and the full models are depicted in Figure $\mathrm{S} 2$. Zr, O, C, and $\mathrm{H}$ atoms are depicted in cyan, red, blue and white, respectively. 

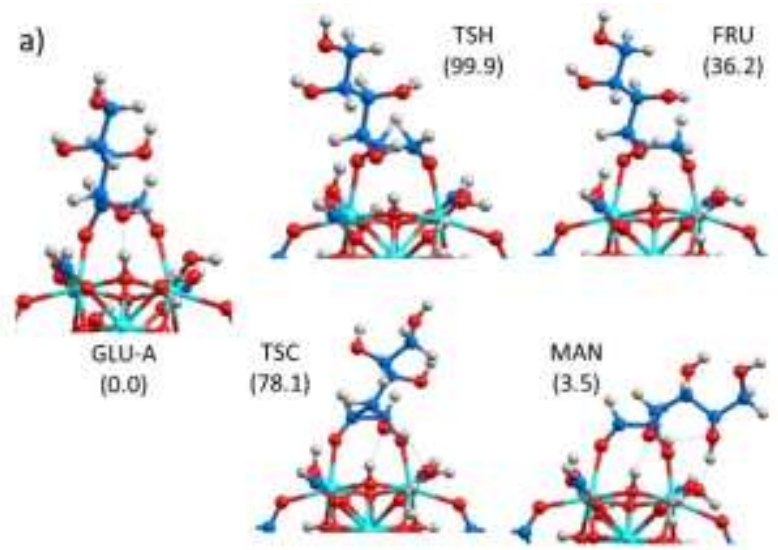

b)
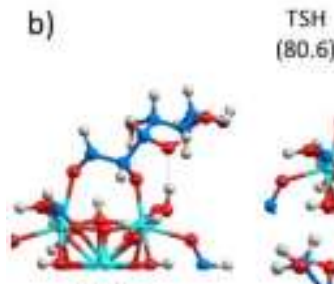

$(80,6)$

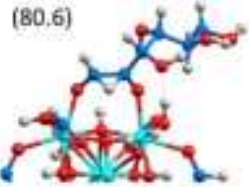

FRU

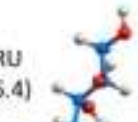

GLU-B

(0.0)

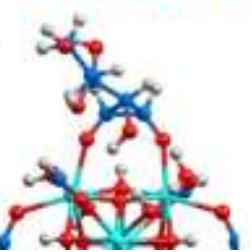

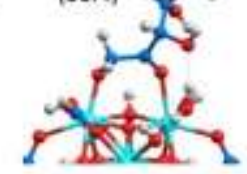

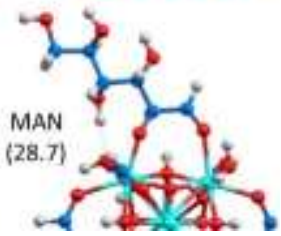

Figure 15. DFT optimized structures of minima and transition states involved in two possible pathways for glucose isomerization and epimerization in Zr-MOF-808, starting from a) GLU-A and b) GLU-B. Relative energies in $\mathrm{kJ} / \mathrm{mol}$ are given in parenthesis. $\mathrm{Zr}$, $\mathrm{O}, \mathrm{C}$, and $\mathrm{H}$ atoms are depicted in cyan, red, blue and white, respectively.

The situation on Zr-MOF-808 is clearly different due to the larger diversity of adsorption modes of glucose associated to the presence of hydroxyl groups and water molecules coordinated to the hexaoxometallic node. Some of these structures and their relative stability are depicted in Figures 14 and S2. The same GLU-A orientation with the $\mathrm{OH}$ group at $\mathrm{C} 3$ hydrogen-bonded to a proton of the $\left[\mathrm{Zr}_{6} \mathrm{O}_{4}(\mathrm{OH})_{4}\right]^{12+}$ node previously described for $\mathrm{UiO}-66(\mathrm{Zr})$ is also found on $\mathrm{Zr}-\mathrm{MOF}-808$, and similar pathways are followed starting from this structure (see Figure 15a). The calculated activation energies are 99.9 and $78.1 \mathrm{~kJ} / \mathrm{mol}$ for the isomerization and epimerization reactions, respectively (see Table 3 ), in relative good agreement with the experimental values $\left(E_{a, \text { isom }}=100 \mathrm{~kJ} / \mathrm{mol}\right.$ and $E_{a, \text { epim }}=88 \mathrm{~kJ} / \mathrm{mol}$, see Figure 6), but incorrectly suggesting that the fructose/mannose molar ratio in $\mathrm{Zr}-\mathrm{MOF}-808$ should be slightly larger than in UiO-66( $\mathrm{Zr})$. However, in structure GLU-B, which is $20 \mathrm{~kJ} / \mathrm{mol}$ more stable than GLU-A (see Figure 14) the OH group at $\mathrm{C} 3$ is interacting with one of the water molecules strongly coordinated to the $\left[\mathrm{Zr}_{6} \mathrm{O}_{4}(\mathrm{OH})_{4}\right]^{12+}$ node. This conformation stabilizes the transition state for the $\mathrm{H}$-shift step but makes more difficult the migration of the $\mathrm{C} 3$ carbon atom, resulting in calculated activation energies of 80.6 and $108.6 \mathrm{~kJ} / \mathrm{mol}$ for the isomerization and epimerization reactions, respectively (see Table 3 and Figure 15b). The large number of possibilities for formation of hydrogen bonds between the hydroxyl groups of glucose and the water molecules and hydroxyl groups coordinated to the $\left[\mathrm{Zr}_{6} \mathrm{O}_{4}(\mathrm{OH})_{4}\right]^{12+}$ node in MOF-808 (some of them are shown in Figures 14 and S2) makes extremely challenging to establish just one preferred pathway from DFT calculations that accurately matches the apparent activation energies determined

experimentally. This would require the use of much more computationally demanding ab initio molecular dynamics simulations. ${ }^{49,50}$ However, it is possible to conclude from the present theoretical study that the bidentate mode of adsorption of deprotonated glucose on $\mathrm{Zr}-\mathrm{MOF}$, involving two $\mathrm{Zr}$ atoms, decreases the activation energy necessary for the C-shift step leading to mannose, which is reflected in a higher mannose/fructose molar ratio as compared to $\mathrm{Zr}$-Beta zeolite.

\section{CONCLUSIONS}

Zr-containing MOFs with MOF-808 and UiO-66 structures are active catalysts for the glucose isomerization and epimerization reactions. Detailed kinetic studies reveal different glucose transformation rates within $\mathrm{Zr}-\mathrm{MOF}$ catalysts. UiO-66(Zr) provides a higher mannose/fructose ratio than $\mathrm{Zr}-\mathrm{MOF}-808$, which is explained by a lower apparent activation energy for glucose epimerization reaction on $\mathrm{UiO}-66(\mathrm{Zr})$ as compared to $\mathrm{Zr}$-MOF808. A ${ }^{13} \mathrm{C}$ NMR mechanistic study using ${ }^{13} \mathrm{C}-\mathrm{C} 1$ labelled glucose confirms that the mannose produced when using both $\mathrm{UiO}-66(\mathrm{Zr})$ and $\mathrm{Zr}-\mathrm{MOF}-808$ is formed by glucose epimerization via 1,2intramolecular carbon shift, while the remarkably lower amount of mannose generated when using $\mathrm{Zr}$-Beta is produced preferentially through a consecutive isomerization of fructose. A computational study of the key steps of the isomerization and epimerization reactions on Zr-MOF-808, UiO-66(Zr) and Zr-Beta catalyst models reveals a different mode of adsorption of deprotonated glucose on Zr-MOF materials, which considerably decreases the activation barrier for the 1,2-intramolecular carbon shift. Finally, NMR and IR spectroscopic techniques using probe molecules combined with DFT calculations allow identifying the Lewis acid sites present in Zr-MOFs and Zr-Beta zeolite, and the particular environments favoring the epimerization of glucose. The structure-activity relationship reported here for glucose transformation reactions using MOFs opens attractive catalyst design routes for attempting to control the active site environment in order to guide the transformation of platform molecules to the desired chemicals through the proper reaction mechanism.

\section{EXPERIMENTAL SECTION \\ Synthesis}

Synthesis of Zr-containing MOF-808 [Zr-MOF-808]. A mixture of $\mathrm{ZrCl}_{4}(0.5 \mathrm{mmol})$ and 1,3,5-benzenetricarboxylic acid $(110 \mathrm{mg}$, $0.5 \mathrm{mmol})$, dimethylformamide (DMF)/formic acid (20 ml:20ml) was sonicated for $30 \mathrm{~min}$. Afterwards, the mixture was added to an autoclave vessel and heated at $100^{\circ} \mathrm{C}$ for $72 \mathrm{~h}$. The resulting white solid was filtered and washed with an excess of DMF and acetone. The as-synthesized material was activated at $120^{\circ} \mathrm{C}$ under vacuum for $12 \mathrm{~h}$.

Synthesis of Zr-containing UiO-66 [UiO-66(Zr)]. A mixture of $\mathrm{ZrCl} 4(0.46 \mathrm{mmol})$, terephthalic acid $(53.4 \mathrm{mg}, 0.46 \mathrm{mmol})$ and formic acid $(1.5 \mathrm{~mL})$ in DMF $(6 \mathrm{~mL})$, was added to an autoclave vessel and heated at $120^{\circ} \mathrm{C}$ for $48 \mathrm{~h}$. The resulting white solid was filtered and washed with an excess of DMF and then acetone. The as-synthesized material was activated at $120^{\circ} \mathrm{C}$ in vacuum for $12 \mathrm{~h}$. Synthesis of Zr-Beta. Zr-Beta with $\mathrm{Si} / \mathrm{Zr} 135$ was prepared according to the literature. ${ }^{51}$ The synthesis procedure was as follows: first, tetraethylammonium hydroxide solution (35 wt\% in water) was mixed with tetraethyl orthosilicate (TEOS), and the mixture was stirred at room temperature for $90 \mathrm{~min}$. Then, an aqueous solution of zirconyl chloride was added and the mixture was left to stir until the ethanol formed upon hydrolysis of TEOS was evaporated. Hydrofluoric acid was added under vigorously stirring until a thick gel was formed. The final gel composition was $1 \mathrm{SiO}_{2}: 0.01 \mathrm{ZrO}_{2}: 0.56 \mathrm{TEAOH}: 0.56 \mathrm{HF}: 7.5 \mathrm{H}_{2} \mathrm{O}$. The gel was 
added to an autoclave and placed in an oven at $140^{\circ} \mathrm{C}$ for 20 days under static conditions. The resulting solid obtained was washed and filtered with water. The resulting $\mathrm{Zr}$-Beta was dried at $100^{\circ} \mathrm{C}$, and then calcined at $580^{\circ} \mathrm{C}$ for $4 \mathrm{~h}$.

\section{Characterization}

Characterization techniques. Powder X-ray diffraction (PXRD) measurements were performed using a Panalytical CubiX diffractometer operating at $40 \mathrm{kV}$ and $35 \mathrm{~mA}$, and using $\mathrm{Cu} \mathrm{K \alpha}$ radiation $(\lambda=0,1542 \mathrm{~nm})$.

Chemical analyses were carried out in a Varian 715-ES ICPOptical Emission spectrometer, after solid dissolution in $\mathrm{HNO}_{3} / \mathrm{HCl} / \mathrm{HF}$ aqueous solution. Elemental analyses were performed by combustion analysis using a Eurovector EA 3000 CHNS analyzer using sulfanilamide as reference.

The morphology of the samples was studied by field emission scanning electron microscopy (FESEM) using a ZEISS Ultra-55 microscope. The sample was mounted on carbon tape stuck on aluminium stubs. Image conditions were $1 \mathrm{kV}$ acceleration voltage and working distance between $(3.1 \mathrm{~mm})$ using the secondary electron detector.

The adsorption and desorption curve of $\mathrm{N}_{2}$ was measured at $77 \mathrm{~K}$ in an ASAP2420 MICROMERITICS device. The specific surface areas were calculated by the Brunauer-Emmet-Teller (BET) with Rouquerol's criterion.

Infrared (FTIR) spectra were recorded in a PIS 100 spectrometer. The solid samples, mixed with $\mathrm{KBr}$, were pressed into a pellet.

Trimethylphosphine oxide (TMPO) dosing. Trimethylphosphine oxide (TMPO) was adsorbed on the different catalysts via dichloromethane solutions. First, all the catalysts were degassed for $4 \mathrm{~h}$ under dynamic vacuum at $120^{\circ} \mathrm{C}$ to remove any adsorbed molecules. They were then transferred to a glovebox to prevent any exposure to moisture. TMPO solutions were prepared with anhydrous dichloromethane in a glovebox. The corresponding quantity of these solutions to obtain the desired TMPO/metal ratios ( $0.15 \mathrm{TMPO} /$ metal ratio for MOFs and $\sim 0.5$ for Zr-Beta) was added to the glass vial containing the materials, and the mixtures were maintained under stirring overnight. Dichloromethane was fully removed by heating at $80^{\circ} \mathrm{C}$ for $4 \mathrm{~h}$. Samples dosed with TMPO were packed under inert atmosphere into zirconia MAS NMR rotors with gastight caps for analysis.

Solid-state ${ }^{31} \mathrm{P}$ MAS NMR spectra were recorded at room temperature under magic angle spinning (MAS) in a Brucker AV400 spectrometer at $161.9 \mathrm{MHz}$ with a spinning rate of $10 \mathrm{kHz}$ and $\pi / 2$ pulse length of $3.7 \mu$ s with spinal proton decoupling and recycle delay of $20 \mathrm{~s} .{ }^{31} \mathrm{P}$ chemical shift was referred to phosphoric acid.

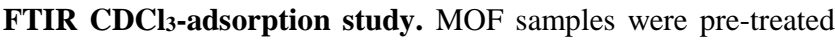
within the IR cell by heating at $120^{\circ} \mathrm{C}$ under vacuum for $1.5 \mathrm{~h}$ before the sorption experiments. Chloroform was then sequentially introduced until saturation before desorption process. FTIR spectra were recorded on a Bruker Vertex 70 spectrometer in the wavenumber range between 400 and $4000 \mathrm{~cm}^{-1}$ with a resolution of $4 \mathrm{~cm}^{-1}$.

\section{Computational details}

The active sites present in the MOFs were simulated by cluster models containing one $\left[\mathrm{Zr}_{6} \mathrm{O}_{4}(\mathrm{OH})_{4}\right]^{12+}$ node and the first shell of organic linkers surrounding them, extracted from the experimental structures of UiO-66 ${ }^{35}$ and MOF-808. ${ }^{37}$ In perfect UiO-66 each node is surrounded by twelve linkers, but only defective sites with a missing linker can display catalytic activity. In MOF-808 each node is connected with six organic linkers, and the excess positive charge is compensated by hydroxyl groups and coordinated water molecules (see Figure 1). The organic linkers of the two MOFs were simulated either by benzoate or by formiate anions. In the first case, the carboxylic groups of the linkers not bonded to the $\left[\mathrm{Zr}_{6} \mathrm{O}_{4}(\mathrm{OH})_{4}\right]^{12+}$ node were replaced by hydrogen atoms and, in a first step, all $\mathrm{C}-\mathrm{H}$ distances were optimized while keeping the positions of all other atoms in the model fixed. Then, in the subsequent geometry optimizations, the five hydrogen atoms of each benzoate group were kept fixed at this optimized positions in order to maintain the structure of the MOF, and all other atoms in the system were allowed to move without restrictions. Smaller models for each MOF were also created in which all organic linkers were simulated by formiate anions, and in this case all atoms in the system were always fully optimized without restrictions.

The active sites in Zr-Beta were simulated by cluster models cut out from the periodic crystalline structure of BEA zeolite and containing one framework $\mathrm{Zr}$ atom at $\mathrm{T} 4$, T5 and $\mathrm{T} 9$ positions bonded to four -O-Si units (closed site) or with one hydrolyzed $\mathrm{Zr}$ $\mathrm{OH}$ bond (open site), as depicted in Figure $\mathrm{S} 1$.

All density functional theory (DFT) calculations were carried out using the M062X functional, ${ }^{52}$ the $6-31 \mathrm{~g}(\mathrm{~d}, \mathrm{p})$ basis set for $\mathrm{O}, \mathrm{C}, \mathrm{P}$ and $\mathrm{H}$ atoms, ${ }^{53,54}$ and the LANL2DZ basis set and pseudopotential for $\mathrm{Zr},{ }^{55,56}$ as implemented in the Gaussian09 software. ${ }^{57}$ In the mechanistic study, geometry optimizations of minima and transition states were carried out without restrictions, and all stationary points were characterized by frequency calculations which also provided the zero-point vibrational corrections to the energy (ZPE). For the simulation of NMR parameters, the isotropic absolute chemical shielding constants $(\sigma)$ were obtained using the gauge including atomic orbitals (GIAO) approach ${ }^{58,59}$ and the ${ }^{31} \mathrm{P}$ chemical shifts were calculated as $\delta_{\text {iso }}\left({ }^{31} \mathrm{P}\right)=\sigma_{\text {ref }}-\sigma$, using phosphoric acid as reference. To improve accuracy, all values were corrected with an equation obtained by fitting $\delta_{\text {iso }}\left({ }^{31} \mathrm{P}\right)$ values at 6 $31 \mathrm{G}(\mathrm{d}, \mathrm{p})$ level against $\delta_{\text {iso }}\left({ }^{31} \mathrm{P}\right)$ values at $6-311++\mathrm{G}(\mathrm{d}, \mathrm{p})$ level for a series of acid-base TMPO adducts (see Table S8 and Figure S5 in the Supporting Information).

\section{Catalytic tests}

Glucose transformation reactions. Reactions with D-glucose were performed in a $3 \mathrm{~mL}$ glass-vessel reactors equipped with a magnetic bar, pressure control and a valve for sample extraction. 1 $\mathrm{g}$ of $10 \mathrm{wt} \% \mathrm{D}$-glucose aqueous solution was added to each reactor containing the corresponding amount of catalyst (25:1 glucose:metal molar ratio for MOFs and 50:1 for Zr-Beta). The mixtures were pressurized with $\mathrm{N}_{2}$ (5 bar), heated up at the corresponding temperature and left to stir. Approximately $30 \mathrm{mg}$ aliquots were taken at different times, diluted with water and filtered with PTFE syringe filter.

The liquid samples obtained from batch reactions were analyzed using HPLC (Varian) equipped with a refractive index detector (RI) Varian Star with an internal temperature of $50^{\circ} \mathrm{C}$ to determine the amount of products and reactants. A Bio-Rad Aminex HPX-87C column was employed for glucose/mannose/fructose separation. The column was maintained at $70^{\circ} \mathrm{C}$ and the mobile phase was $100 \%$ Milli-Q water at a flow rate of $0.5 \mathrm{ml} / \mathrm{min}$. Glucose conversions and product yields were determined using external calibration curves with standard solutions of known concentration. Calculations of kinetic rate constants and activation energies. Glucose to fructose and glucose to mannose are equilibrium reactions ( $\mathrm{G} \leftrightarrow \mathrm{F}$ and $\mathrm{G} \leftrightarrow \mathrm{M}$ ). However, since only the points at 
low conversions have been considered, it can be assumed that they are two parallel pseudo-first-order reactions $(\mathrm{G} \rightarrow \mathrm{F}$ and $\mathrm{G} \rightarrow \mathrm{M})$ :

$$
\begin{gathered}
\frac{d[\mathrm{G}]}{d \mathrm{t}}=-\left(k_{\text {isom, } F}+k_{\text {epim }, M}\right) \cdot[\mathrm{G}] \quad \text { (Eq. 1) } \\
\left.\frac{d[\mathrm{~F}]}{d \mathrm{t}}=k_{\text {isom }, F} \cdot[\mathrm{G}] \quad \text { (Eq. } 2\right) \\
\left.\frac{d[\mathrm{M}]}{d \mathrm{t}}=k_{\text {epim }, M} \cdot[\mathrm{G}] \quad \text { (Eq. } 3\right)
\end{gathered}
$$

The integration of Eq. 1 results in the following equation:

$$
\ln \left(\frac{[\mathrm{G}]}{[\mathrm{G}]_{0}}\right)=-\left(k_{\text {isom }, F}+k_{\text {epim }, M}\right) \cdot \mathrm{t} \quad \text { (Eq. 4) }
$$

The slope of the representation of $\ln \left([\mathrm{G}] /[\mathrm{G}]_{0}\right)$ versus $t$ allows the calculation of the $\left(k_{\text {isom }, F}+k_{\text {epim }, M}\right)$.

The integration of Eq. 2 and 3 results in the following equations:

$$
\begin{aligned}
\frac{[\mathrm{F}]}{[\mathrm{G}]_{0}} & =\frac{k_{\text {isom }, F}}{\left(k_{\text {isom }, F}+k_{\text {epim }, M}\right)} \cdot\left(1-e^{-\left(k_{\text {isom }, F}+k_{\text {epim }, M}\right) \cdot t}\right) \\
\frac{[\mathrm{M}]}{[\mathrm{G}]_{0}} & =\frac{k_{\text {epim }, M}}{\left(k_{\text {isom }, F}+k_{\text {epim }, M}\right)} \cdot\left(1-e^{-\left(k_{\text {isom }, F}+k_{\text {epim }, M}\right) \cdot t}\right)
\end{aligned}
$$

From Eq. 5 and Eq. 6:

$$
\frac{[\mathrm{F}]}{[\mathrm{M}]}=\frac{k_{\text {isom }, F}}{k_{\text {epim }, M}} \quad \text { (Eq. 7) }
$$

The combination of Eq. 4 and Eq. 7 allows the calculation of the kinetic rate constants $k_{i s o m, F}$ and $k_{\text {epim, }}$.

The activation energy, Ea, can be calculated from the Arrhenius equation:

$$
k=A e^{-E a / R T}(\text { Eq. 8) }
$$

where: $\mathrm{k}$ is the observed rate constant; $\mathrm{A}$ is the pre-exponential factor; Ea is the activation energy $(\mathrm{J} / \mathrm{mol}) ; \mathrm{R}$ is the Universal gas constant $(8.3144621 \mathrm{~J} / \mathrm{mol} \cdot \mathrm{K})$; and $\mathrm{T}$ is the temperature $(\mathrm{K})$.

The Eq. 8 can be linearized by the logarithmic transformation of the dependent variable:

$$
\ln (k)=\ln (A)-\frac{E a}{R}\left(\frac{1}{T}\right)(\text { Eq. 9) }
$$

The representation of $1 / \mathrm{T}$ versus $\ln (\mathrm{k})$ allows the calculation of the activation energy (Ea).

Mechanistic experiments. Reactions with ${ }^{13} \mathrm{C}-\mathrm{C} 1$-glucose were performed in a $3 \mathrm{~mL}$ glass-vessel reactors equipped with a magnetic bar, pressure control and a valve for sample extraction. 1 $\mathrm{g}$ of $1 \mathrm{wt} \%{ }^{13} \mathrm{C}-\mathrm{C} 1$-glucose in water was added to the reactor containing the corresponding amount of catalyst (1.2:1 glucose:metal molar ratio for MOFs and 50:1 for Zr-Beta) to assure similar glucose conversion values. The mixtures were pressurized with $\mathrm{N}_{2}$ (5 bar), heated up at $90^{\circ} \mathrm{C}$ and left to stir during $2 \mathrm{~h}$. The reaction mixtures were quenched with ice, filtered with PTFE syringe filter and diluted with $\mathrm{D}_{2} \mathrm{O}$. The measured glucose conversions for $\mathrm{Zr}-\mathrm{MOF}-808$, UiO-66(Zr) and $\mathrm{Zr}$-Beta under these conditions were $11.4,8.4$ and $9.6 \%$, respectively.

${ }^{13} \mathrm{C}$ NMR were recorded on a Bruker 300 spectrometer at spinning rate of $15 \mathrm{kHz}$ with a $90^{\circ}$ pulse length of $5 \mu \mathrm{s}$ using high-power proton decoupling (spinal64) $\mu$ s with $20 \mathrm{~s}$ repetition time and the chemical shifts are reported in ppm relative to residual proton solvents signals.

\section{ASSOCIATED CONTENT}

\section{Supporting Information}

DFT optimized structures of TMPO interacting with Zr-Beta, UiO66(Zr) and Zr-MOF-808 and calculated ${ }^{31} \mathrm{P}$ isotropic chemical shifts, and DFT optimized structures and calculated bond lengths of monosaccharides and transition states for isomerization (TSH) and epimerization (TSC) on the different catalysts.

\section{AUTHOR INFORMATION}

\section{Corresponding Author}

Manuel Moliner, mmoliner@itq.upv.es Mercedes Boronat, boronat@itq.upv.es

\section{ORCID}

Sergio Rojas-Buzo: 0000-0002-7257-1027

Avelino Corma: 0000-0002-2232-3527

Mercedes Boronat: 0000-0002-6211-5888

Manuel Moliner: 0000-0002-5440-716X

\section{Notes}

The authors declare no competing financial interest.

\section{ACKNOWLEDGMENT}

This work has been supported by the European Union through ERC-AdG-2014-671093 (SynCatMatch), by Spanish Government through "Severo Ochoa" (SEV-2016-0683, MINECO), MAT2017-82288-C2-1-P (AEI/FEDER, UE) and RTI2018101033-B-I00 (MCIU/AEI/FEDER, UE) and by Generalitat Valenciana through AICO/2019/060. The Electron Microscopy Service of the UPV is also acknowledged for their help in sample characterization.

\section{REFERENCES}

(1) Gallezot, P. Conversion of Biomass to Selected Chemical Products. Chem. Soc. Rev. 2012, 41 (4), 1538-1558. https://doi.org/10.1039/C1CS15147A.

(2) Corma, A.; Iborra, S.; Velty, A. Chemical Routes for the Transformation of Biomass into Chemicals. Chem. Rev. 2007, $107 \quad$ (6), 2411-2502. https://doi.org/10.1021/cr050989d.

Isikgor, F. H.; Becer, C. R. Lignocellulosic Biomass: A Sustainable Platform for the Production of Bio-Based Chemicals and Polymers. Polym. Chem. 2015, 6 (25), 4497-4559. https://doi.org/10.1039/C5PY00263J.

Román-Leshkov, Y.; Davis, M. E. Activation of Carbonyl-Containing Molecules with Solid Lewis Acids in Aqueous Media. ACS Catal. 2011, 1 (11), 1566-1580. https://doi.org/10.1021/cs200411d.

Moliner, M. State of the Art of Lewis Acid-Containing Zeolites: Lessons from Fine Chemistry to New Biomass Transformation Processes. Dalton Transactions. 2014, pp 4197-4208. https://doi.org/10.1039/c3dt52293h.

Belščak-Cvitanović, A.; Komes, D.; Dujmović, M.; Karlović, S.; Biškić, M.; Brnčić, M.; Ježek, D. Physical, Bioactive and Sensory Quality Parameters of Reduced Sugar Chocolates Formulated with Natural Sweeteners as Sucrose Alternatives. Food Chem. 2015, 167, 61-70. https://doi.org/10.1016/j.foodchem.2014.06.064.

Nikolla, E.; Román-Leshkov, Y.; Moliner, M.; Davis, M. E. "One-Pot" Synthesis of 5-(Hydroxymethyl)Furfural from Carbohydrates Using Tin-Beta Zeolite. ACS Catal. 2011, 1 (4), 408-410. https://doi.org/10.1021/cs2000544. Kovalevsky, A. Y.; Hanson, L.; Fisher, S. Z.; Mustyakimov, M.; Mason, S. A.; Trevor Forsyth, V.; Blakeley, M. P.; Keen, D. A.; Wagner, T.; Carrell, H. L.; Katz, A. K.; Glusker, J. P.; Langan, P. Metal Ion Roles and the Movement of Hydrogen during Reaction Catalyzed by D-Xylose Isomerase: A Joint X-Ray and Neutron Diffraction Study. Structure 2010, 18 (6), 688699. https://doi.org/10.1016/j.str.2010.03.011.

(9) Corma, A.; Nemeth, L. T.; Renz, M.; Valencia, S. Sn- 
Zeolite Beta as a Heterogeneous Chemoselective Catalyst for Baeyer-Villiger Oxidations. Nature 2001, 412 (6845), 423-425. https://doi.org/10.1038/35086546.

(10) Corma, A.; Domine, M. E.; Valencia, S. Water-Resistant Solid Lewis Acid Catalysts: Meerwein-Ponndorf-Verley and Oppenauer Reactions Catalyzed by Tin-Beta Zeolite.

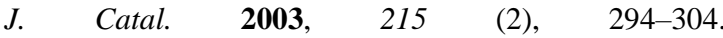
https://doi.org/10.1016/S0021-9517(03)00014-9.

(11) Moliner, M.; Román-Leshkov, Y.; Davis, M. E. TinContaining Zeolites Are Highly Active Catalysts for the Isomerization of Glucose in Water. Proc. Natl. Acad. Sci. U. S. A. 2010, 107 (14), 6164-6168. https://doi.org/10.1073/pnas.1002358107.

(12) Román-Leshkov, Y.; Moliner, M.; Labinger, J. A.; Davis, M. E. Mechanism of Glucose Isomerization Using a Solid Lewis Acid Catalyst in Water. Angew. Chem. Int. Ed. 2010, 49 (47), 8954-8957. https://doi.org/10.1002/anie.201004689.

(13) Gunther, W. R.; Wang, Y.; Ji, Y.; Michaelis, V. K.; Hunt, S. T.; Griffin, R. G.; Román-Leshkov, Y. Sn-Beta Zeolites with Borate Salts Catalyse the Epimerization of Carbohydrates via an Intramolecular Carbon Shift. Nat. Commun. 2012, 32 (1), 1109. https://doi.org/10.1038/ncomms2122.

(14) Park, C.-S.; Kim, J.-E.; Choi, J.-G.; Oh, D.-K. Characterization of a Recombinant Cellobiose 2Epimerase from Caldicellulosiruptor Saccharolyticus and Its Application in the Production of Mannose from Glucose. Appl. Microbiol. Biotechnol. 2011, 92 (6), 11871196. https://doi.org/10.1007/s00253-011-3403-3.

(15) Bermejo-Deval, R.; Gounder, R.; Davis, M. E. Framework and Extraframework Tin Sites in Zeolite Beta React Glucose Differently. ACS Catal. 2012, 2 (12), 2705-2713. https://doi.org/10.1021/cs300474x.

(16) Zhang, Y.; Chen, H.; Gao, Y.; Yao, Z.; Wang, J.; Zhang, B.; Luo, K.; Du, S.; Su, D. S.; Zhang, J. MoO x Nanoparticle Catalysts for d -Glucose Epimerization and Their Electrical Immobilization in a Continuous Flow Reactor. ACS Appl. Mater. Interfaces 2019, 11 (47), 44118-44123. https://doi.org/10.1021/acsami.9b13848.

(17) Hu, H.; Liu, S.; Zhang, W.; An, J.; Xia, H. Efficient Epimerization of Glucose to Mannose over MolybdenumBased Catalyst in Aqueous Media. ChemistrySelect 2020, 5 (5), 1728-1733. https://doi.org/10.1002/slct.201903417.

(18) Megías-Sayago, C.; Álvarez, E.; Ivanova, S.; Odriozola, J. A. Epimerization of Glucose over Ionic Liquid/Phosphomolybdate Hybrids: Structure-Activity Relationship. Green Chem. 2018, 20 (5), 1042-1049. https://doi.org/10.1039/C7GC03738D.

(19) Ventura, M.; Cecilia, J. A.; Rodríguez-Castellón, E.; Domine, M. E. Tuning Ca-Al-Based Catalysts' Composition to Isomerize or Epimerize Glucose and Other Sugars. Green Chem. 2020, 22 (4), 1393-1405. https://doi.org/10.1039/C9GC02823D.

(20) Delidovich, I.; Palkovits, R. Catalytic Isomerization of Biomass-Derived Aldoses: A Review. ChemSusChem 2016, 9 (6), 547-561 https://doi.org/10.1002/cssc.201501577.

(21) Bermejo-Deval, R.; Orazov, M.; Gounder, R.; Hwang, S.J.; Davis, M. E. Active Sites in Sn-Beta for Glucose Isomerization to Fructose and Epimerization to Mannose. ACS Catal. 2014, 4 (7), 2288-2297. https://doi.org/10.1021/cs500466j.

(22) Li, S.; Josephson, T.; Vlachos, D. G.; Caratzoulas, S. The Origin of Selectivity in the Conversion of Glucose to Fructose and Mannose in Sn-BEA and Na-Exchanged SnBEA Zeolites. J. Catal. 2017, 355, 11-16. https://doi.org/10.1016/j.jcat.2017.09.001

(23) Furukawa, H.; Cordova, K. E.; O’Keeffe, M.; Yaghi, O. M. The Chemistry and Applications of Metal-Organic Frameworks. Science 2013, 341 (6149), 1230444 1230444. https://doi.org/10.1126/science.1230444.

(24) Gascon, J.; Corma, A.; Kapteijn, F.; Llabrés i Xamena, F. $\mathrm{X}$. Metal Organic Framework Catalysis: Quo Vadis ? ACS Catal. 2014, 4 (2), 361-378. https://doi.org/10.1021/cs400959k.

(25) Cirujano, F. G. MOFs vs. Zeolites: Carbonyl Activation with M( Iv ) Catalytic Sites. Catal. Sci. Technol. 2017, 7 (23), 5482-5494. https://doi.org/10.1039/C7CY01811H.

(26) Rojas-Buzo, S.; García-García, P.; Corma, A. Hf-Based Metal-Organic Frameworks as Acid-Base Catalysts for the Transformation of Biomass-Derived Furanic Compounds into Chemicals. Green Chem. 2018, 20 (13), 3081-3091. https://doi.org/10.1039/C8GC00806J.

Guo, Q.; Ren, L.; Kumar, P.; Cybulskis, V. J.; Mkhoyan, K. A.; Davis, M. E.; Tsapatsis, M. A Chromium Hydroxide/MIL-101(Cr) MOF Composite Catalyst and Its Use for the Selective Isomerization of Glucose to Fructose. Angew. Chem. Int. Ed. 2018, 57 (18), 49264930. https://doi.org/10.1002/anie.201712818.

(28) Oozeerally, R.; Ramkhelawan, S. D. K.; Burnett, D. L.; Tempelman, C. H. L.; Degirmenci, V. ZIF-8 Metal Organic Framework for the Conversion of Glucose to Fructose and 5-Hydroxymethyl Furfural. Catalysts 2019, 9 (10), 812. https://doi.org/10.3390/catal9100812.

(29) Yabushita, M.; Li, P.; Islamoglu, T.; Kobayashi, H.; Fukuoka, A.; Farha, O. K.; Katz, A. Selective MetalOrganic Framework Catalysis of Glucose to 5Hydroxymethylfurfural Using Phosphate-Modified NU1000. Ind. Eng. Chem. Res. 2017, 56 (25), 7141-7148. https://doi.org/10.1021/acs.iecr.7b01164.

(30) Yan, C.; Zhang, Y.; Da, Z.; Wie, Y.; Li, B.; Meng, M.; Yuan, S.; Yan, Y. Synthesis and Evaluation of Acid-base Bi-functional MOFs Catalyst Supported on PVDF Membrane for Glucose Dehydration to 5-HMF. ChemistrySelect 2019, 4 (45), 13182-13190. https://doi.org/10.1002/slct.201903356.

(31) Oozeerally, R.; Burnett, D. L.; Chamberlain, T. W.; Walton, R. I.; Degirmenci, V. Exceptionally Efficient and Recyclable Heterogeneous Metal-Organic Framework Catalyst for Glucose Isomerization in Water. ChemCatChem 2018, $10 \quad$ (4), 706-709. https://doi.org/10.1002/cctc.201701825.

(32) Gong, J.; Katz, M. J.; Kerton, F. M. Catalytic Conversion of Glucose to 5-Hydroxymethylfurfural Using ZirconiumContaining Metal-Organic Frameworks Using Microwave Heating. RSC Adv. 2018, 8 (55), 3161831627. https://doi.org/10.1039/C8RA06021E.

(33) Rojas-Buzo, S.; García-García, P.; Corma, A. Catalytic Transfer Hydrogenation of Biomass-Derived Carbonyls over Hafnium-Based Metal-Organic Frameworks. ChemSusChem 2018, $11 \quad$ (2), 432-438. https://doi.org/10.1002/cssc.201701708.

(34) Luo, Q.; Zhang, Y.; Qi, L.; Scott, S. L. Glucose Isomerization and Epimerization over Metal-Organic Frameworks with Single-Site Active Centers. ChemCatChem 2019, 11 (7), 1903-1909. https://doi.org/10.1002/cctc.201801889.

(35) Cavka, J. H.; Jakobsen, S.; Olsbye, U.; Guillou, N.; Lamberti, C.; Bordiga, S.; Lillerud, K. P. A New Zirconium Inorganic Building Brick Forming Metal Organic Frameworks with Exceptional Stability. J. Am. Chem. Soc. 2008, 130 (42), 13850-13851. https://doi.org/10.1021/ja8057953. 
Moon, S.-Y.; Liu, Y.; Hupp, J. T.; Farha, O. K Instantaneous Hydrolysis of Nerve-Agent Simulants with a Six-Connected Zirconium-Based Metal-Organic Framework. Angew. Chem. Int. Ed. 2015, 54 (23), 67956799. https://doi.org/10.1002/anie.201502155.

(37) Furukawa, H.; Gándara, F.; Zhang, Y.-B.; Jiang, J.; Queen, W. L.; Hudson, M. R.; Yaghi, O. M. Water Adsorption in Porous Metal-Organic Frameworks and Related Materials. J. Am. Chem. Soc. 2014, 136 (11), 4369-4381. https://doi.org/10.1021/ja500330a.

(38) Cliffe, M. J.; Wan, W.; Zou, X.; Chater, P. A.; Kleppe, A. K.; Tucker, M. G.; Wilhelm, H.; Funnell, N. P.; Coudert, F.-X.; Goodwin, A. L. Correlated Defect Nanoregions in a Metal-Organic Framework. Nat. Commun. 2014, 5 (1), 4176. https://doi.org/10.1038/ncomms5176.

(39) Liu, Y.; Klet, R. C.; Hupp, J. T.; Farha, O. Probing the Correlations between the Defects in Metal-Organic Frameworks and Their Catalytic Activity by an Epoxide Ring-Opening Reaction. Chem. Commun. 2016, 52 (50), 7806-7809. https://doi.org/10.1039/C6CC03727E.

(40) Cybulski, A.; Kuster, B. F. M.; Marin, G. B. The Kinetics of the Molybdate-Catalysed Epimerization of D-Glucose and D-Mannose in Aqueous Solutions. J. Mol. Catal. 1991, 68 (1), 87-103. https://doi.org/10.1016/03045102(91)80063-9.

(41) Ju, F.; VanderVelde, D.; Nikolla, E. Molybdenum-Based Polyoxometalates as Highly Active and Selective Catalysts for the Epimerization of Aldoses. ACS Catal. 2014, 4 (5), 1358-1364. https://doi.org/10.1021/cs401253z.

(42) Rajabbeigi, N.; Torres, A. I.; Lew, C. M.; Elyassi, B.; Ren, L.; Wang, Z.; Je Cho, H.; Fan, W.; Daoutidis, P.; Tsapatsis, M. On the Kinetics of the Isomerization of Glucose to Fructose Using Sn-Beta. Chem. Eng. Sci. 2014, 116, 235-242. https://doi.org/10.1016/j.ces.2014.04.031.

(43) Bermejo-Deval, R.; Assary, R. S.; Nikolla, E.; Moliner, M.; Román-Leshkov, Y.; Hwang, S.-J.; Palsdottir, A.; Silverman, D.; Lobo, R. F.; Curtiss, L. A.; Davis, M. E. Metalloenzyme-like Catalyzed Isomerizations of Sugars by Lewis Acid Zeolites. Proc. Natl. Acad. Sci. U. S. A. 2012, 109 (25), 9727-9732. https://doi.org/10.1073/pnas.1206708109.

(44) Hayes, M. L.; Pennings, N. J.; Serianni, A. S.; Barker, R. Epimerization of Aldoses by Molybdate Involving a Novel Rearrangement of the Carbon Skeleton. J. Am. Chem. Soc. 1982, 104 (24), 6764-6769. https://doi.org/10.1021/ja00388a047.

(45) Zheng, A.; Liu, S.-B.; Deng, F. 31 P NMR Chemical Shifts of Phosphorus Probes as Reliable and Practical Acidity Scales for Solid and Liquid Catalysts. Chem. Rev. 2017, 117 (19), 12475-12531. https://doi.org/10.1021/acs.chemrev.7b00289.

(46) Lewis, J. D.; Ha, M.; Luo, H.; Faucher, A.; Michaelis, V. K.; Román-Leshkov, Y. Distinguishing Active Site Identity in Sn-Beta Zeolites Using 31 P MAS NMR of Adsorbed Trimethylphosphine Oxide. ACS Catal. 2018, 8 (4), $3076-3086$. https://doi.org/10.1021/acscatal.7b03533.

(47) Caratelli, C.; Hajek, J.; Cirujano, F. G.; Waroquier, M.; Llabrés i Xamena, F. X.; Van Speybroeck, V. Nature of Active Sites on UiO-66 and Beneficial Influence of Water in the Catalysis of Fischer Esterification. J. Catal. 2017, 352, 401-414. https://doi.org/10.1016/j.jcat.2017.06.014.
(54) Hehre, W. J.; Ditchfield, R.; Pople, J. A. Self-Consistent Molecular Orbital Methods. XII. Further Extensions of Gaussian-Type Basis Sets for Use in Molecular Orbital Studies of Organic Molecules. J. Chem. Phys. 1972, 56 (5), 2257-2261. https://doi.org/10.1063/1.1677527.

(55) Hay, P. J.; Wadt, W. R. Ab Initio Effective Core Potentials for Molecular Calculations. Potentials for the Transition Metal Atoms Sc to Hg. J. Chem. Phys. 1985, 82 (1), 270 283. https://doi.org/10.1063/1.448799.

(56) Hay, P. J.; Wadt, W. R. Ab Initio Effective Core Potentials for Molecular Calculations. Potentials for $\mathrm{K}$ to $\mathrm{Au}$ Including the Outermost Core Orbitals. J. Chem. Phys. 1985, 82 (1), 299-310. https://doi.org/10.1063/1.448975.

(57) Frisch, M. J.; Trucks, G. W.; Schlegel, H. B.; Scuseria, G. E.; Robb, M. A.; Cheeseman, J. R.; Scalmani, G.; Barone, V.; Mennucci, B.; Petersson, G. A.; Nakatsuji, H.; Caricato, M.; Li, X.; Hratchian, H. P.; Izmaylov, A. F.; Bloino, J.; Zheng, G.; Sonnenberg, J. L.; Had, M.; Fox, D. J. Gaussian 09. Gaussian, Inc.: Wallingford CT 2009. Ditchfield, R. Self-Consistent Perturbation Theory of Diamagnetism. Mol. Phys. 1974, 27 (4), 789-807. https://doi.org/10.1080/00268977400100711.

Wolinski, K.; Hinton, J. F.; Pulay, P. Efficient Implementation of the Gauge-Independent Atomic Orbital Method for NMR Chemical Shift Calculations. J. Am. Chem. Soc. 1990, 112 (23), 8251-8260. https://doi.org/10.1021/ja00179a005. 


\section{For Table of Contents Use Only}

Synopsis: The combination of spectroscopic, kinetic and theoretical studies allows unraveling the nature of the metal sites in Zr-MOFs catalysts for glucose transformation reactions.

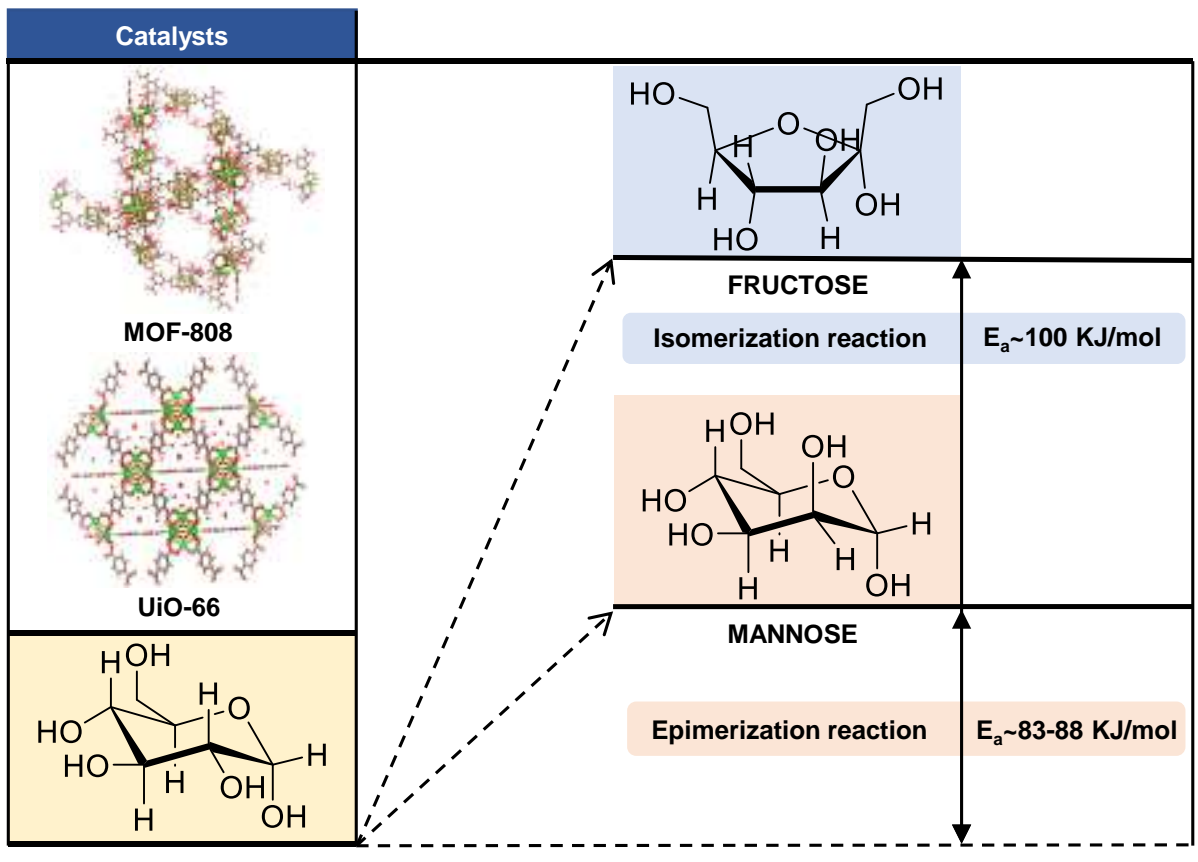

GLUCOSE 